\title{
Revealing the meteorological drivers of the September 2015 severe dust event in the Eastern Mediterranean
}

\author{
Philipp Gasch $^{1}$, Daniel Rieger ${ }^{1, a}$, Carolin Walter ${ }^{1}$, Pavel Khain $^{2}$, Yoav Levi ${ }^{2}$, Peter Knippertz ${ }^{1}$, and Bernhard Vogel ${ }^{1}$ \\ ${ }^{1}$ Karlsruhe Institute of Technology, Institute of Meteorology and Climate Research, Karlsruhe, Germany \\ ${ }^{2}$ Israel Meteorological Service, Bet Dagan, Israel \\ ${ }^{a}$ now at: Deutscher Wetterdienst, Frankfurter Str. 135, 63067 Offenbach, Germany \\ Correspondence to: Philipp Gasch (philipp.gasch@kit.edu)
}

Received: 5 January 2017 - Discussion started: 3 February 2017

Revised: 15 September 2017 - Accepted: 19 September 2017 - Published: 15 November 2017

\begin{abstract}
In September 2015 one of the severest and most unusual dust events on record occurred in the Eastern Mediterranean. Surprisingly, operational dust transport models were unable to forecast the event. This study details the reasons for this failure and presents simulations of the event at convection-permitting resolution using the modelling system ICON-ART. The results allow for an in-depth analysis of the influence of the synoptic situation, the complex interaction of multiple driving atmospheric systems and the mineral dust radiative effect on the dust event. A comparison of the results with observations reveals the quality of the simulation results with respect to structure and timing of the dust transport. The forecast of the dust event is improved decisively. The event is triggered by the unusually early occurrence of an active Red Sea trough situation with an easterly axis over Mesopotamia. The connected sustained organized mesoscale convection produces multiple cold-pool outflows responsible for intense dust emissions. Complexity is added by the interaction with an intense heat low, the inland-penetrating Eastern Mediterranean sea breeze and the widespread occurrence of supercritical flow conditions and subsequent hydraulic jumps in the vicinity of the Dead Sea Rift Valley. The newly implemented mineral dust radiation interaction leads to systematically more intense and faster propagating coldpool outflows.
\end{abstract}

\section{Introduction}

Mineral dust aerosol plays an important role for the environment. The transport of mineral dust within the atmosphere has an effect on physical processes, chemical composition and biological systems on various temporal and spatial scales (Carslaw et al., 2010; Shao et al., 2011a; Boucher et al., 2013). Therefore, a need exists to correctly represent mineral dust and its effects in atmospheric models.

In the Eastern Mediterranean the impact of mineral dust on the environment, human population and traffic is important due to the unique environmental setting and great population density. Dust events in the Eastern Mediterranean (EM) are usually associated with strong south-westerly and southerly flows in the region, although events have been reported under easterly flow conditions (Dayan et al., 1991; Levi and Rosenfeld, 1996). As a result, the most important remote dust source regions for the EM are situated in northeastern Africa and the southern Arabian peninsula (Ganor, 1991; Kubilay et al., 2000). According to a subjective classification conducted by Dayan et al. (2008), the synoptic-scale systems associated with dust transport towards the EM are Cyprus lows $(60 \%)$, Sharav cyclones $(12 \%)$ and Red Sea troughs (12\%). Consequently, the number of dust events in the EM is correlated with cyclone activity in the region (Kishcha et al., 2016, and references therein). Long-range mineral dust transport towards the EM peaks during the transitional seasons in spring and autumn (Offer and Goossens, 2001), when low-pressure systems and their associated fronts occur most frequently in the region (Singer et al., 2003, and references therein; Dayan et al., 2008). Resulting from the climatology of dust events in the EM, many studies investigate and simu- 

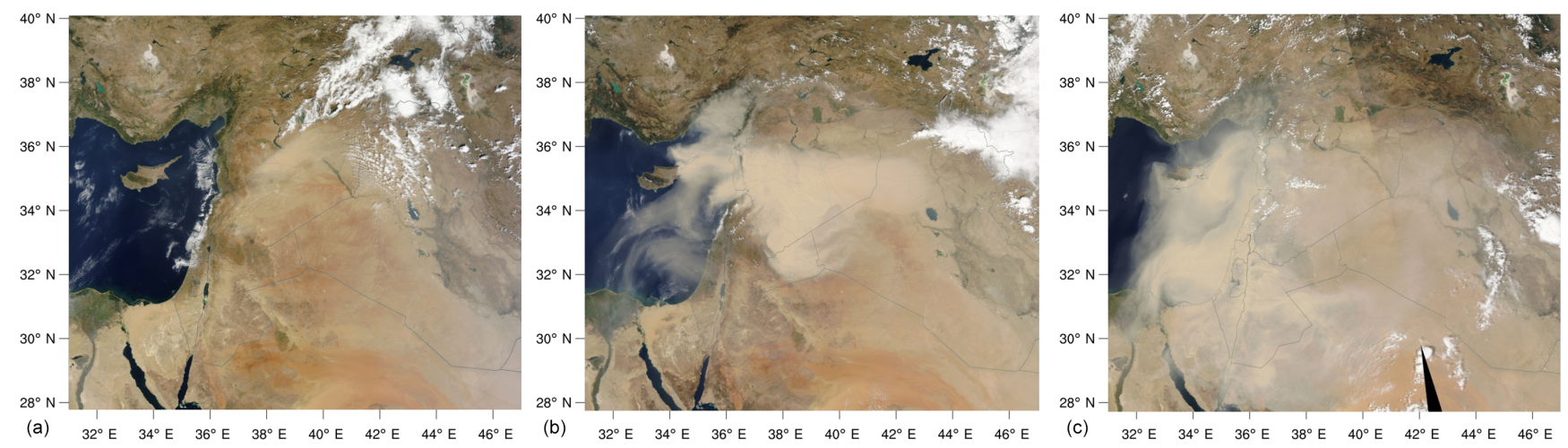

Figure 1. MODIS VIS satellite images of the EM region, at (a) 08:15 UTC, 6 September, (b) 10:35 UTC, 7 September, and (c) 11:18 UTC, 8 September 2015 (NASA Worldview, 2016).

late dust events in connection with low-pressure systems and long-range transport of mineral dust from the Sahara towards the EM (Vogel et al., 2006; Spyrou et al., 2013; Rémy et al., 2015; Kishcha et al., 2016).

In September 2015 an exceptional dust event occurred in the EM. The impact of the event on the EM region was severe, with five people reported to have died, hundreds hospitalized and daily life as well as traffic in the region disrupted (NASA Earth Observatory, 2015; The Weather Channel, 2015; Times Of Israel, 2015). The event was remarkable with respect to magnitude, timing, duration and dust transport direction. In Israel, dust surface concentrations were more than 100 times the normal value, exceeding $5000 \mu \mathrm{g} \mathrm{m}^{-3}$ at some stations. The Israeli Meteorological Service stated that it was the first time in 75 years that a dust storm had reached Israel in early September and lasted beyond 1 day (Alpert et al., 2016). In an analysis of measurements from Cyprus, Mamouri et al. (2016) also report dust surface concentrations close to $8000 \mu \mathrm{g} \mathrm{m}^{-3}$, with maximum aerosol optical thickness (AOD) values above 5 retrieved by the Moderate Resolution Imaging Spectroradiometer (MODIS). Based on a statistical classification of strong and extreme dust events in the Mediterranean from satellite observations by Gkikas et al. (2016), Mamouri et al. (2016) rank the event as "recordbreaking". They report an observed multilayered dust plume structure, indicating a complex event evolution with multiple dust emission sequences.

Satellite images for the visible part of the electromagnetic spectrum (VIS) from MODIS illustrate the evolution of the dust storm (Fig. 1). Starting from 6 September 2015, high dust concentrations were observed over Syria. On 7 September, the full Mesopotamia region and the northern part of the EM was covered by a thick dust layer. Large amounts of dust were transported into the southern EM region during the following night, consequently covering the complete EM on 8 September 2015. The dust plume remained detectable in the region over the course of the next 7 days (Alpert et al., 2016; Mamouri et al., 2016). As discussed above, the prop- agation direction of the record dust storm into the EM from the east is very unusual and so is the duration of the event.

Adding to the extraordinariness, operational global dust transport models were unable to forecast the event as also noted by Mamouri et al. (2016). All predictions provided through the World Meteorological Organization's Sand and Dust Storm Warning Advisory and Assessment System (SDS-WAS, http://sds-was.aemet.es) initialized at 12:00 UTC, 7 September, failed to simulate significant dust concentrations in the EM region for 12:00 UTC, 8 September. The simulated values of the dust optical depth in the EM are between 0.1 and 0.4 in the multi-model mean with a standard deviation of $0.1-0.2$. The forecast failure is highly problematic due to the severe impact of the event.

From EUMETSAT (European Organisation for the Exploitation of Meteorological Satellites) SEVIRI (Spinning Enhanced Visual and Infrared Imager) satellite observations, the development of organized mesoscale convective systems (MCSs) which produced cold-pool outflows (CPOs) over Mesopotamia is detectable. The CPOs and their interaction with a heat low have been suggested as important drivers for the observed dust emissions by Kerkmann et al. (2015). Suspecting a failure of the operational models due to their nonconvection-permitting set-up, Solomos et al. (2017) model the event using a convection-permitting nest over the SyriaIraq-Iran-Turkey border region. In their simulations, they find that the dust generation is related to the combined effect of a strong thermal low over Syria and convective outflows, finally leading to a westward-moving large dust cloud. They propose that the intrusion of moist and unstable air masses from the Arabian Sea and the Red Sea favoured the convective outbreak. Furthermore, they demonstrate a large sensitivity to the specification of dust source strength in their model.

A number of studies have shown that the inability to represent organized mesoscale convection and the related CPOs in models with parametrized convection can lead to a substantial underestimation of dust emissions. Analysing simulations for summertime West Africa, Marsham et al. (2011) 
show that only convection-permitting models are able to resolve an afternoon peak in a parameter termed "uplift potential", which is closely related to dust emission. Heinold et al. (2013) model off-line dust emission and estimate the contribution of different meteorological systems using largedomain convection-permitting simulations during a 40-day period, also for summertime West Africa. Corroborating Marsham et al. (2011), they find that approximately $40 \%$ of dust emissions can be linked to CPOs, highlighting the need for convection-permitting resolution modelling. In another in-depth study of CPOs, Pantillon et al. (2016) analyse yearlong convection-permitting simulations in the Sahara region. They conclude that in this region the contribution of convective CPOs to dust uplift potential is on the order of one-fifth of the annual budget, with substantially higher proportions of up to one-third over the summer months. In summary, CPOs have been identified as important systems contributing to dust emission (Knippertz et al., 2007; Marsham et al., 2011; Heinold et al., 2013; Pantillon et al., 2016), and their occurrence has been documented for all major dust source regions worldwide (Knippertz, 2014).

Dust radiative effects in general have been shown to be of great importance for atmospheric processes (Pérez et al., 2006; Heinold et al., 2008; Bangert et al., 2012; Rémy et al., 2015). Given the large impact of CPOs on lower-tropospheric dust concentrations as well as temperature and humidity, it is an interesting question what role radiative modifications associated with CPOs play in their dynamical evolution. A first mechanism is intensively studied by Redl et al. (2016), showing that surface temperatures in CPOs can be higher than in the surrounding air masses at night. This counter-intuitive behaviour is due to increased cloud coverage inside the CPO and due to the dynamical breakup of the stable night-time inversion in the surface layers by increased turbulent mixing. The result is a downward transport of energy and reduced cooling of the surface, which in turn radiates this energy into space. The overall effect is a loss of energy from the lower boundary layer in the initial stages of cold-pool development. Redl et al. (2016) also investigate a second effect of higher humidity within the cold air-mass leading to increased downwelling longwave radiation on the order of $5 \mathrm{~W} \mathrm{~m}^{-2}$ and thereby warming of the lowest layer. They state that this effect becomes increasingly important in the later stages of CPO development after the dynamical effects diminish. The reduced stratification of the CPO in the lowest layers can result in increased vertical mixing, turbulence and drag, leading to a faster decay. A third effect, which is not included in the model of Redl et al. (2016), is the emission of mineral dust due to the high wind speeds and its subsequent interaction with radiation. This is expected to reduce incoming shortwave radiation during daytime and increase downwelling atmospheric longwave radiation during nighttime. Mineral dust can thereby feed back to boundary layer dynamics, which in turn can alter dust processes (Heinold et al., 2008; Rémy et al., 2015). The missing radiative effect of mineral dust is also a limitation in the study of Heinold et al. (2013) discussed above. Kalenderski and Stenchikov (2016) include and investigate the mineral dust radiative effect in their convection-permitting simulation of a CPO in the Red Sea region. Extensively comparing their model results to observations, they find generally good agreement in modelled dust plume structure. They report significant reductions of up to $301.4 \mathrm{~W} \mathrm{~m}^{-2}$ in incoming solar radiation and longwave radiation increases of up to $9.0 \mathrm{~W} \mathrm{~m}^{-2}$ at the surface due to mineral dust. However, Kalenderski and Stenchikov (2016) do not systematically investigate the mineral dust radiative feedback to the $\mathrm{CPO}$ structure.

In this paper, we present a detailed analysis of the September 2015 severe dust event in the EM. We combine observations from satellites and the ground with new high-resolution simulations using the ICON-ART (Icosahedral Nonhydrostatic - Aerosol and Reactive Trace gases) global modelling system (Zängl et al., 2015; Rieger et al., 2015). It is capable of local grid refinements; in this study the finest nest has a convection-permitting grid spacing of $2.5 \mathrm{~km}$. The ART extension (Rieger et al., 2015) allows for on-line simulation of dust processes in ICON. An on-line mineral dust radiation interaction scheme has been implemented in ICON-ART as part of this study. Expanding on previous work, we use a large two-way nested convection-permitting domain covering large parts of the Middle East and adjacent EM $(2000 \mathrm{~km}$ diameter). This allows a realistic enough representation of the complicated interactions between convective processes and the regional-scale circulation for an in-depth analysis of the meteorological mechanisms involved in creating this highly unusual event. This will also aid a better understanding of the forecast failure of operational dust models. In addition, using model sensitivity experiments, we analyse for the first time the impact of dust radiative effects on the evolution of the event. The specific research questions addressed are as follows: (1) Is the forecast of the dust event improved by running convection-permitting simulations? (2) How does the synoptic situation relate to its exceptional character? (3) What are the meteorological drivers responsible for the pickup and long-range transport of mineral dust during this event? (4) How does the mineral dust radiative effect influence the dust event in general and the evolution of the CPOs in particular?

\section{Model description}

ICON is a non-hydrostatic modelling system developed jointly by the German Weather Service (DWD) and the Max Planck Institute for Meteorology (Zängl et al., 2015). It solves the full three-dimensional non-hydrostatic and compressible Navier-Stokes equations for all domains. Thereby, ICON can serve as a unified global numerical weather prediction model and climate modelling system, enabling seamless prediction from the global to local scale with a unified set 
of model physics. Its major advantages over previous model generations used at DWD, and especially important for atmospheric tracer studies, are the exact local mass conservation achieved by solving a prognostic equation for density and the mass-consistent tracer transport achieved by transporting time-averaged mass fluxes computed from the dynamical core and diagnostic reintegration of the mass continuity equation. ICON allows for flexible local grid refinements (nests) with two-way interactions between the respective grids. Furthermore, it features a better scalability on massively parallel computer architectures. Since January 2015 ICON is used for operational weather forecasting at DWD. The ART module is an extension of ICON developed at the Institute of Meteorology and Climate Research at the Karlsruhe Institute of Technology. An overview of the module is given by Rieger et al. (2015). ART is capable of simulating a variety of aerosol species, e.g. volcanic ash, sea salt and radioactive substances. In addition, atmospheric chemistry processes, e.g. two species of very short-lived bromocarbons, a linearized ozone chemistry and photolysis are also available in ART. For the tracer transport simulations, the modelling capabilities of ICON are of crucial importance because the same physical parametrization packages can be used from a global to regional scale. Thereby, inconsistencies in tracer concentrations arising from differences in tracer advection and physical parametrizations between the driving model and the high-resolution model can be avoided.

The size distribution of mineral dust is represented by three modes in ART. For each mode the integral values of specific number and mass are the prognostic variables. The distribution of specific number and mass with particle size during transport is described using log-normal distributions for each mode with the diagnostic median diameter of the mass distribution and constant geometric standard deviation as parameters (Mode A, $d=1.5 \mu \mathrm{m}, \sigma=1.7$; Mode B, $d=6.7 \mu \mathrm{m}, \sigma=1.6$; Mode C, $d=14.2 \mu \mathrm{m}, \sigma=1.5$ ). The processes which affect mineral dust number and/or mass concentrations in ART are gravitational settling (sedimentation), deposition due to turbulent diffusion and wet deposition due to washout. The scheme used for the emission of mineral dust in ART is described in Rieger (2016). It is based on an emission scheme introduced by Vogel et al. (2006). Compared to the original version three improvements were implemented. These are (1) the global availability of soil properties (size distribution, residual soil moisture), (2) accounting for the soil dispersion state and (3) a tile approach used to account for soil type heterogeneity at coarse resolutions. For the equations used the reader is referred to the work by Rieger (2016). The scheme parametrizes the threshold friction velocity above which dust emission can occur according to Shao and Lu (2000). They base their description on a physical balance between aerodynamic drag and lift causing upward-directed forces and cohesion and gravity causing downward-directed forces on particles. The effect of surface roughness and soil moisture is accounted for through parametrizations by Raupach (1993) and Fécan et al. (1999), respectively, which modify the threshold friction velocity. The regional distribution of soil types used for dust emission in ART is taken from the Harmonized World Soil Database (HWSD) with a resolution of 30 arcsec (Nachtergaele and Batjes, 2012). The fraction of erodible soil is determined assuming that certain land use classes from the GlobCover2000 dataset (Arino et al., 2008) contribute to mineral dust emission, whereas others do not, with snow generally prohibiting emissions. The land use classes which can contribute to emission are regions with sparse vegetation, bare areas, closed to open grass- and shrublands, furthermore mosaic forest/grassland and shrubland. In order to retain the high spatial resolution of the dataset for ART a tile approach is used for calculating dust emissions. The tile approach calculates the overall emission in every grid box as a weighted average of the emissions from different soil types based on their fractional coverage of the grid box. Determination of land use classes is difficult in the Levantine region. It has undergone drastic change in recent years due to ongoing conflict (Gleick, 2014), problems in transboundary water management (Voss et al., 2013) and a drought period (Notaro et al., 2015). Therefore, widespread, previously cultivated areas exist which are now available to erosion and known to be efficient dust sources (Solomos et al., 2017). The physical parametrization for mineral dust emission in ICON-ART relies on soil type and land cover information from external datasets as stated above. Hence, the recent land cover changes as described above are not reflected in the datasets used by ICON-ART. Therefore, this can result in an underestimation of dust emission.

\subsection{Mineral dust radiative effect}

As a part of this study the on-line dust radiative effect has been implemented in ICON-ART. It is now possible to include the radiative effect of the current, local dust concentration from ART at every grid point and time step in ICON instead of the previously used dust climatology. Through its feedback to radiative fluxes the dust influences atmospheric state, thereby providing a feedback loop back to dust processes again (Tegen et al., 2006; Heinold et al., 2008; Shao et al., 2011a). The implementation was done for the standard radiation scheme utilized by ICON, which is the Rapid Radiative Transfer Model (RRTM), described by Mlawer et al. (1997). The ART dust radiation routine is called at every time step at which the RRTM is called by ICON.

Without ART, ICON uses a climatological distribution of aerosols (e.g. mineral dust, sea salt, stratospheric aerosol) to include their radiative effect. When using ART, any of these aerosol species can be calculated on-line, and therefore its radiative effect can be included with much better accuracy. For aerosol species not simulated by ART the climatological values are still used and taken from ICON. Therefore, the radiative transfer parameters provided by ART to the RRTM 
are combined values from the local ART aerosol concentration plus the ICON climatology, which is used only for the aerosol species not simulated. For example, in our study we simulated mineral dust using ART and therefore can include the on-line mineral dust radiative feedback. For the sea salt and stratospheric aerosol radiative effect, however, the climatological values from ICON are used.

The radiative transfer parameters needed consist of the optical depth, single scattering albedo and asymmetry parameter. In order to obtain the on-line mineral dust radiative feedback, the local radiative transfer parameters are calculated using the dust optical properties and the local dust mass concentration at every grid point and for every level as detailed in Stanelle et al. (2010). The radiative transfer parameters are calculated in ART and provided to the RRTM, where they feed back to the atmospheric state in ICON.

For consideration of the on-line dust radiative effect, the dust optical properties need to be determined. The mineral dust optical properties are computed with the help of Mie calculations using the complex refractive index of mineral dust (Bohren and Huffman, 1983; Petty, 2006; Wagner et al., 2012). This study therefore assumes sphericity as well as a spatially invariant mineral composition of the mineral dust particles. Although this assumption is generally not fulfilled for single mineral dust particles (Otto et al., 2009; Kahnert et al., 2007), it introduces negligible errors for a population of randomly oriented non-spherical particles if only albedo and flux-related quantities are calculated (Mishchenko et al., 1995, 1997). Due to the random orientation a collection of particles scatters light in a similar way to a spherical particle because the individual differences disappear in the angular integration (Tegen and Lacis, 1996). Therefore, Mie calculations are able to provide a good representation of scattering even for non-spherical particles.

The spatially invariant mineral composition of dust in ICON-ART means we assume similarity to Saharan dust everywhere. Studies have shown that mineral dust optical properties can depend on the source region (Petzold et al., 2009), which presents a great uncertainty for the radiative forcing as discussed in Myhre and Stordal (2001). For our region of interest, Nisantzi et al. (2015) find differences in the dust particle lidar ratios in a comparison of dust from the Middle East and the Sahara. Two problems prevent a more detailed description of the mineral dust optical properties for our study. First, there is a lack of observations of the refractive index for our dust source region, and the variance within source regions can be considerable (Petzold et al., 2009). Second, to the best of our knowledge a dataset of the earth's crust mineralogical composition for our region is missing so far, making a more detailed availability of refractive indices futile. However, the influence of differences in the refractive indices is small compared to the influence of a varying size distribution (Myhre and Stordal, 2001), and this latter effect is represented in ICON-ART.
The values of the refractive index used to conduct the Mie calculations are the same ones used by Stanelle et al. (2010) for COSMO (Consortium for Small-scale Modelling)-ART and are therefore not detailed further.

For the Mie calculations a code developed by Bond et al. (2006) was used, this in turn utilizes a subset developed by Mätzler (2002) for the calculation of the Mie scattering coefficients and truncation of the series. The code was adapted to allow for the processing of multiple wavelengths and averaging to the RRTM wavebands in a post-processing step.

The mineral dust optical properties are calculated for three modes and 30 RRTM radiation wavebands. Results of Mie calculations for the ART mineral dust modes are shown in Fig. 2 and are comparable to those published in other studies (Tegen and Lacis, 1996; Helmert et al., 2007; Rémy et al., 2015). Although the authors use slightly different size distributions and refractive index properties, the results are very similar to the ones presented here.

The optical properties of mineral dust are highly dependent on its particle size distribution represented through three log-normal modes in ART. From the six prognostic variables in ART, the specific dust mass and number concentration for each of the three modes, a median diameter can be diagnosed for each mode. Due to different processes such as gravitational settling acting differently on the specific dust mass and number concentrations in ART, the diagnostic median diameter of each mode changes during transport (the standard deviation of each mode is kept constant). In a physical sense, the most important effect is large particles settling out faster due to sedimentation, which results in mostly smaller particles being transported to distant regions within each mode. Therefore, the median diameter of each mode is expected to decrease during transport. Consequently, a new polynomial parametrization of the optical properties per waveband was introduced to account for the change in median diameter during the transport processes. In a post-processing step a thirdorder polynomial is fitted to the results of multiple Mie calculations for median diameters between 0.25 and 1.25 times the initial median diameter of the count number distribution. This is done for every mode and every RRTM waveband. The polynomial fit parameters are initialized in ICON-ART and used for the determination of optical properties at every grid point with the diagnosed median diameter being the independent variable.

The specifics of the mineral dust radiative effect implementation are available upon request and detailed in Gasch (2016).

\subsection{Model set-up}

In this study ICON-ART is run in a set-up with one global domain and four nests, with two-way feedback for the meteorological parameters enabled for all domains. Each domain presents a stand-alone model run which obtains its lateral boundary conditions from the coarser domain. For the global 

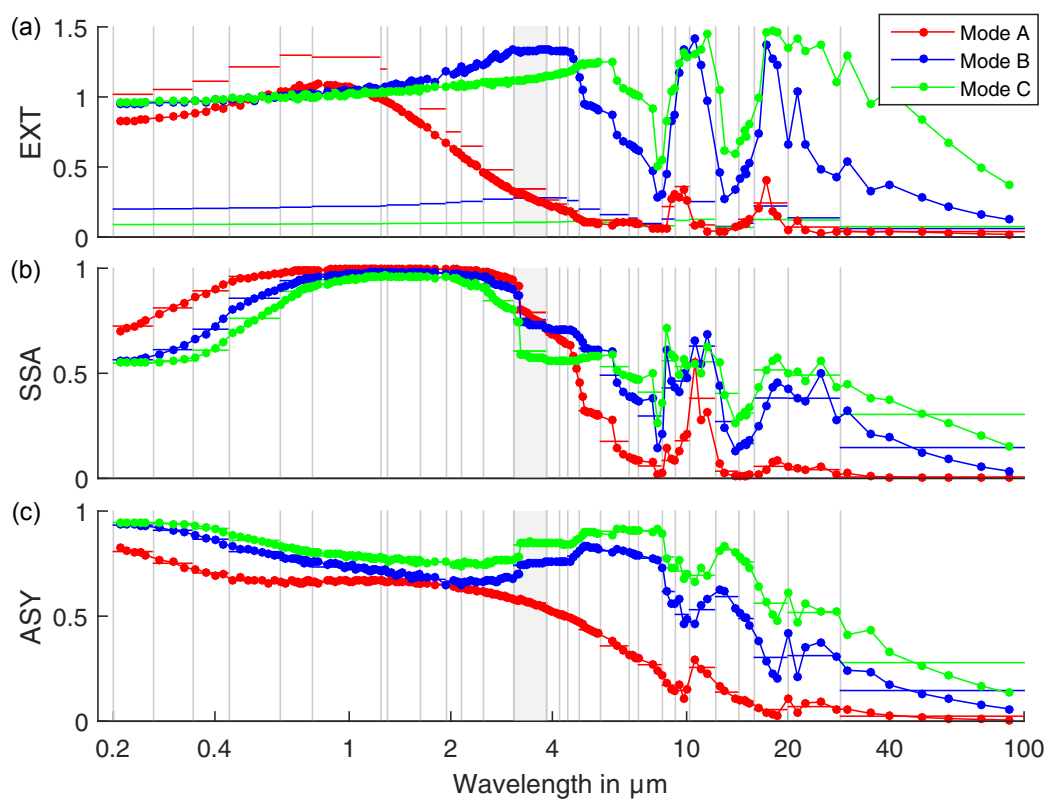

Figure 2. Results from Mie calculations as used by ICON-ART. Points are normalized with respect to the value at $550 \mathrm{~nm}$; horizontal lines show absolute values. Shown are (a) the extinction coefficient (EXT) in $\mathrm{m}^{2} \mathrm{~g}^{-1}$, (b) the single scattering albedo (SSA) and (c) the asymmetry parameter (ASY) for all modes. The borders of the RRTM radiation scheme wavebands are outlined as grey lines in the background. The filled grey band represents the waveband present both in the longwave and shortwave part of the RRTM.

domain, an R2B6 grid is used. This corresponds to an effective grid spacing of $40 \mathrm{~km}$ (Zängl et al., 2015). For every nest, the grid point distance is halved, thereby ending at R2B10 with an effective grid spacing of $2.5 \mathrm{~km}$. The finest domain is circular shaped and centred at $35^{\circ} \mathrm{N}, 40^{\circ} \mathrm{E}$ with a radius of approximately $1000 \mathrm{~km}$, thus containing 507100 grid points. In order to realistically represent organized moist, deep convection, a convection-permitting model resolution is required. A grid spacing of $2.5 \mathrm{~km}$ is generally assumed to be sufficient to permit the development of convection in a nonhydrostatic model. Therefore, the convection parametrization, including the parametrization for shallow convection, is switched off for the finest grid. In our set-up for the finest resolution, the advection/fast physics time step is $18 \mathrm{~s}$ with a sub-stepping of the dynamics at $4.5 \mathrm{~s}$. RRTM is called every $288 \mathrm{~s}$ for the finest resolution.

In the global domain the model consists of 90 levels extending up to the mesosphere, with the lowest level being at $20 \mathrm{~m}$ and the highest level at $75 \mathrm{~km}$. For the nests the simulated atmosphere extends into the stratosphere up to $22.5 \mathrm{~km}$, containing 60 vertical levels.

For the cloud microphysical processes, the two-moment cloud scheme is used (Seifert and Beheng, 2006), as this was found to lead to more realistic features of the mesoscale organized convection. The two-moment scheme utilizes a parametrization developed by Seifert and Beheng (2001) which predicts number and mass concentrations for six different hydrometeor species. These are cloud droplets, rain drops, cloud ice, snow, graupel and hail. For this parametriza- tion an extension was developed by Rieger (2016), which includes the aerosol effect on cloud formation through using the current, local aerosol mass and number concentrations from ART. The aerosol-cloud microphysics interaction is not included in this study as it creates a new set of research questions and the focus in this study is on the mineral dust radiation interaction. The combined effects of the mineral dust radiation interaction and its impact on cloud microphysics are investigated and quantified in a separate publication for a different event (Rieger et al., 2017).

ICON-ART is initialized with analysis fields from the Integrated Forecasting System (IFS) of the European Centre for Medium-Range Weather Forecasts (ECMWF). A limitation with initializing from the IFS analysis datasets is that the IFS has a horizontal grid spacing of approximately $13 \mathrm{~km}$ and is therefore non-convection-permitting. Thus, when re-initializing ICON-ART with the current meteorological fields any previously existing organized convection is terminated. The IFS initialization data for soil moisture were modified in a region along the Syrian-Iraqi border which showed high soil moisture values and spatial inhomogeneities without preceding rain or changes in soil properties. Therefore, in a region from $37.5-41.5^{\circ} \mathrm{N}$ and $32.5-35^{\circ} \mathrm{E}$, the soil moisture index in the four layers provided by the IFS is set to the average value of the region between $36.5-38^{\circ} \mathrm{N}$ and $32-34^{\circ} \mathrm{E}$. This is done in order to prevent a possible effect of soil moisture on dust emission in this region, where dust emission is likely to be underestimated due to the recent changes in land use conditions (see Sect. 2). The region mod- 
ified is an important dust source region and emission fluxes for mineral dust increased due to the reduction in the soil moisture content.

The ICON-ART mineral dust concentrations are passed on to the next run whenever a re-initialization of the meteorological fields from an IFS analysis is performed. No assimilation of mineral dust concentrations from observations takes place. Hence, the runs are performed as free runs for the mineral dust concentrations with a frequent update of the meteorological background conditions from IFS analysis in order to benefit from the data assimilation performed therein. A 2-week spin-up simulation is performed starting on 23 August 2015 in order to achieve a realistic background concentration for mineral dust on the global domain. Another re-initialization from an IFS analysis is performed at 00:00 UTC, 4 September, to obtain a realistic background concentration of mineral dust in the finer domains for the simulations starting at 18:00 UTC, 5 September. From 00:00 UTC, 6 September, onwards, a multitude of partially overlapping events takes place, which need to be simulated correctly in order to obtain a realistic dust distribution in the EM. Therefore, the time chosen for initialization is of crucial importance due to the aforementioned termination of organized convection. Various options were examined, the times chosen for initialization are 18:00 UTC, 5 September, and 12:00 UTC, 6 September.

For the investigation of the dust radiative effect, two simulations are performed. The first is the simulation including the on-line radiation interaction with mineral dust from ART which is called "ARI" (aerosol radiation interaction) in the following. The second is a simulation in which the mineral dust concentrations are multiplied by 0 in the ART routine calculating the radiative effect of dust. This simulation is called "CTRL" (control) in the following; it contains no mineral dust influence on radiation at all. In this study only the mineral dust radiation interaction is simulated on-line by ART; for all other aerosols the default climatologies are used in all runs.

\section{Simulation results and validation}

For the global grid, ICON-ART produces results comparable to those from other global models. However, due to its flexible nesting capability, it allows for convection-permitting simulations for the finest resolution. As is shown in this section, ICON-ART is thereby able to resolve the meteorological drivers of the event in great detail. The results show that the dust event consists of multiple stages and is created by the interaction of different meteorological systems. A comparison of model results to available satellite observations highlights the ICON-ART simulation quality.

\subsection{Synoptic situation}

For the event simulated, the synoptic conditions in the Middle East are distinctively different from the normal summer situation as the ICON-ART model results show. An overview of the modelled synoptic situation is provided in Fig. 3 at 18:00 UTC, 6 September, as at this point in time all relevant synoptic features are detectable.

The usually dominant Persian trough (Bitan and Sa'Aroni, 1992) is not present. Instead, a low-level synoptic pattern termed Red Sea trough (RST) with an eastern axis is apparent below $800 \mathrm{hPa}$, which extends northward from the Red Sea towards central Syria under easterly flow conditions. The direction of the trough axis and its position over the Red Sea make it plausible to attribute it to the RST category rather than to the Persian trough category. Furthermore, a characteristic strong southerly flow exists in the Mesopotamia region, which is crucial for the sustained lifetime of the mesoscale organized convection as it advects hot and moist air from the Persian Gulf. The RST is accompanied by a midtropospheric trough between 700 and $400 \mathrm{hPa}$ extending far southward into the EM under westerly flow conditions. The trough axis runs approximately along the Dead Sea Rift Valley, curving east towards Egypt in the southern part. East of this trough (downstream), high wind speeds of up to $20 \mathrm{~m} \mathrm{~s}^{-1}$ exist in a streak running from south-west towards north-east. The streak is situated exactly upstream of the mesoscale convective system (MCS) development region. As suggested in previous studies (Krichak et al., 2012; Vries et al., 2013), this marked jet could provide significant moisture transport for the MCS from the Red Sea and Africa in the form of an atmospheric river with high values of atmospheric humidity. At upper-tropospheric levels above $400 \mathrm{hPa}$ a shortwave trough exists in the region above Syria. This trough advects positive vorticity and cold air into the region at high altitudes, thereby creating quasi-geostrophic, forced ascent and potential instability, respectively. In addition, the strong wind shear between lower and upper levels in the Mesopotamia region produces the conditions necessary for MCSs by enabling a separation of up- and downdraught. In combination with the orographic lifting by the Zagros mountain range, the position of the slowly eastward-moving trough enables the development of mesoscale organized convection and determines its position throughout the event. The combination of a low-level RST extending northward and upper-tropospheric troughs extending southward into the EM has been termed an active RST in previous studies due to its high potential for severe weather (Krichak et al., 2012; Vries et al., 2013). The timing of the active RST synoptic situation is exceptional, as the RST usually starts to occur only by late September or early October (Alpert et al., 2004; Tsvieli and Zangvil, 2005), although events have been documented in August and September (Osetinsky, 2006). The active RST has been linked to severe weather phenomena in the EM and the Arabian peninsula in connection with atmospheric rivers transporting large 

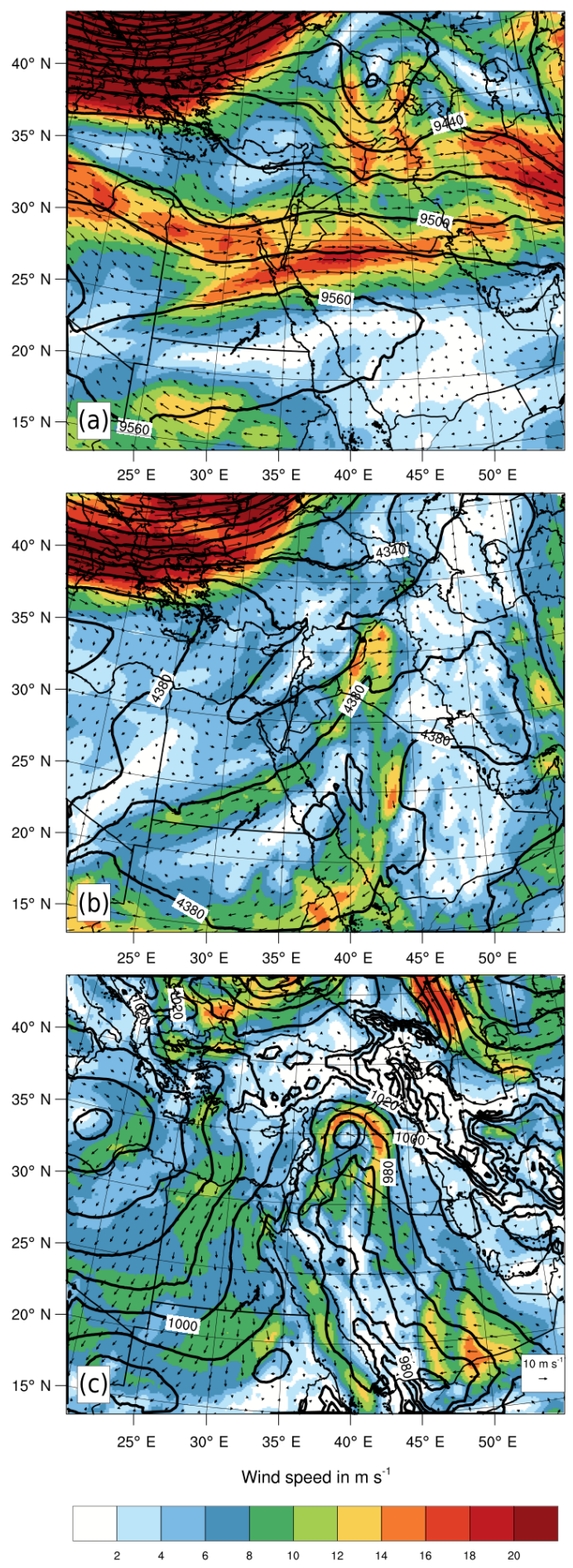

Figure 3. Synoptic situation on 6 September at 18:00 UTC as simulated by ICON-ART for the global domain. Shown are the (a) $300 \mathrm{hPa}$, (b) $600 \mathrm{hPa}$ and (c) $900 \mathrm{hPa}$ levels. Black lines denote the height of the respective pressure level in geopotential metres. Wind speed is colour-coded, and wind velocity is shown as vectors. quantities of precipitable water from eastern Africa, although the specific moisture sources are still debated (Vries et al., 2013, and references therein). The clustering of convectively active days with mesoscale convective organization is often observed during active RST situations (Krichak et al., 2012; Vries et al., 2013). This clustering is also in agreement with a study by Miller et al. (2008), who investigate haboob characteristics in the Arabian peninsula.

As discussed in Sect. 3.2, the active RST enables the interaction of multiple dust-emitting meteorological systems over the course of 3 days, which explains the extraordinariness of the event with respect to magnitude and spatial extent. The unusual transport direction of the dust plume from Syria and Iraq into the EM from the east is caused by the downstream flank of the RST. To our knowledge, the active RST synoptic situation has previously not been linked to severe dust events in the EM and the exceptional character of this event is emphasized by a comparison with climatological studies (Singer et al., 2003; Alpert et al., 2004; Dayan et al., 2008). While Solomos et al. (2017) already pointed out the importance of the advection of moist and warm air and orographic triggering for the September 2015 case, the discussion above additionally underlines the importance of the unusual active RST situation to create the severe dust event.

\subsection{Course of events}

In the following, a detailed analysis of the development stages and responsible atmospheric drivers, which lead to the severe dust event, is provided. We focus on the results from the convection-permitting domain, as it yields remarkable improvements compared to the global domain using convective parametrization (not shown), consistent with the work by Marsham et al. (2011) and Heinold et al. (2013). For the finest domain, the simulated convection and its interaction with dust emission is investigated in depth. Unfortunately, the region where the MCS and the first stages of the CPOs occur are located in the Syria-Iraq border region, which is not covered by a meteorological observation network. Therefore, no surface observations are available and the event can only be analysed using satellite data, which nevertheless yields interesting results. Figure 4 provides a schematic depiction of the event stages as well as their horizontal extent and course, which are referred to in the following.

\section{First cold-pool outflow, heat low and Eastern Mediterranean sea breeze}

During the night from 5 to 6 September 2015, a convective system exists over the Turkey-Syria border region. It is fuelled by the inflow along the eastern side of the RST. The system moves towards the north-east along with the mean flow direction above $500 \mathrm{hPa}$. Due to the favourable position of the convective system in front of the mid-tropospheric through axis, it intensifies during the course of the night. 


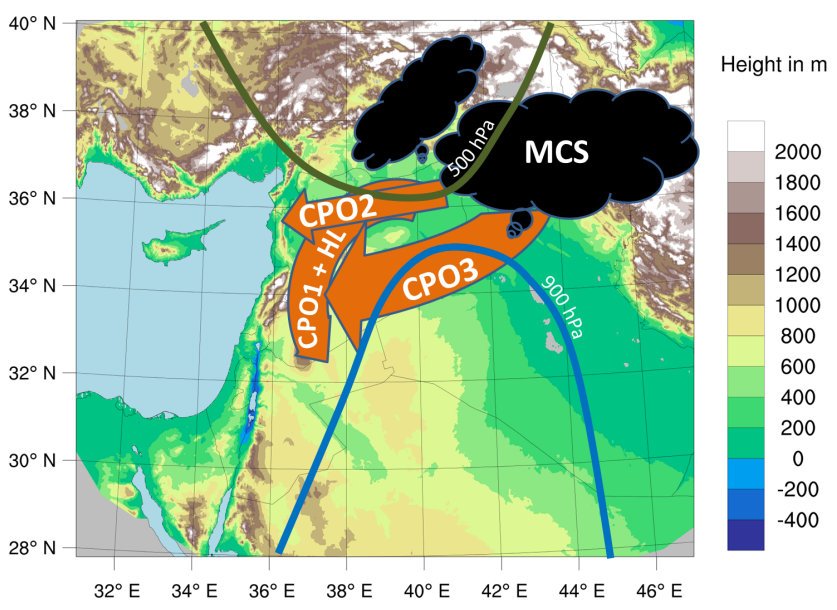

Figure 4. Schematic depiction the main dust event stages and atmospheric features. The topography as used by the finest domain is colour-coded. Coloured lines represent average geopotential height of pressure levels. Labels refer to the description used in the text. Arrow size corresponds to event magnitude and arrowhead size to event speed.

However, in contrast to subsequent systems, it lacks the full mesoscale organization of convection, possibly due to less favourable wind-shear conditions. During the early morning hours of 6 September 2015, the convective system produces a first, weak cold-pool outflow (termed CPO1 in the following) which remains decoupled from the surface due to the stable nocturnal boundary layer. As soon as the sun rises, the downward mixing of momentum increases and dust is picked up (a comparison of ICON-ART modelling results with satellite observations is shown in Fig. A1). The high surface wind speeds are intensified and sustained during the day by a strong and shallow heat low (HL) forming in the developing boundary layer. The heat low is located in the tip of the RST and centred above Syria where temperatures on 6 September reach values above $45^{\circ} \mathrm{C}$. The maximum AOD value observed by MODIS is 2.78 , compared to a dust optical depth (DOD) of 2.41 modelled by ICON-ART in good spatial agreement. Differences in the AOD distribution from MODIS and DOD from ART over the EM are attributable to background aerosol (e.g. sea salt, black carbon), which is not represented in our simulation but measured by MODIS. It should be noted that MODIS can suffer from a systematic bias for AODs $>2.5$, resulting in an AOD overestimation in the range of 0.5 to 1.5 as shown by Mamouri et al. (2016) through a comparison of MODIS and AERONET (Aerosol Robotic Network) data in the region. This is in stark contrast to the model results by Solomos et al. (2017, their Fig. 4c), who simulate AOD values above 20 as early as 00:00 UTC on 6 September 2015 with two distinct maxima.

During the course of the day, the flow structure created by the CPO1 in combination with the heat low above Syria interacts with the inland-penetrating sea breeze from the Mediter- ranean Sea, creating strong southward transport of dust towards Jordan. From 10:00 UTC onwards, the atmospheric instability created by boundary layer heating and upper-level cold air advection is released and deep convection starts to develop over the Syria-Iraq border region and Zagros mountain range in the RST inflow region. From SEVIRI Meteosat satellite images a second, convective cold-pool outflow (CPO2) which travels west from the Zagros mountain range is detectable at 12:00 UTC. This CPO2 travels fast towards the west in the RST flow structure and is supported by the heat low. The re-initialization of ICON-ART with IFS at 12:00 UTC impairs the CPO2 development due to the termination of convective structures (see Sect. 2.2). However, the main flow structures are still captured as the subsequent development shows.

The lifting caused by the gust front of the $\mathrm{CPO} 2$ triggers the initiation of deep convection over the Syria-Iraq border region which organizes into an MCS around 18:00 UTC. By this time the $\mathrm{CPO} 2$ has already travelled far into Syria. The MCS starts to develop a marked, third cold-pool outflow (CPO3) from 20:00 UTC onwards. The CPO3 travels in the wake of the $\mathrm{CPO} 2$, but in a more southerly direction. The strong third cold-pool flow towards the south counters the inflow from southerly directions along the eastern flank of the RST, thereby lifting the warm and moist air masses. This evolution differs markedly from the simulations by Solomos et al. (2017, their Fig. 7b), who find a northward travelling small cold-pool structure around 15:00 UTC on 6 September 2015, which triggers secondary convective cells in their model. A comparison of ICON-ART model results and SEVIRI RGB dust product observations as well as CALIPSO ((Cloud-Aerosol Lidar and Infrared Pathfinder Satellite Observations) backscatter measurements is shown in Figs. A2 and $\mathrm{A} 3$. In addition, there are four cross sections through ICON-ART results along which the event evolution and vertical structure can be tracked for all points in time discussed in this paper. The first cross section runs from $35^{\circ} \mathrm{N}, 32^{\circ} \mathrm{E}$ to $35^{\circ} \mathrm{N}, 46^{\circ} \mathrm{E}$ along the $35^{\circ} \mathrm{N}$ circle of latitude, thereby providing insight into the east-west transport over Syria towards the northern EM (Fig. A4, left). The second cross section runs from $32^{\circ} \mathrm{N}, 34^{\circ} \mathrm{E}$ to $38^{\circ} \mathrm{N}, 46^{\circ} \mathrm{E}$ along the main southwestward dust plume travel direction, thereby providing insight into dust transport towards the southern EM (Fig. A4, right). The third and fourth cross sections run along both the CALIPSO overpass tracks (Fig. A5).

Past midnight on 7 September, explosive intensification of the MCS takes places due to the favourable atmospheric conditions. It develops a sharply defined, curved rainfall pattern in front of which the $\mathrm{CPO} 3$ is strongly intensified. In connection with the only slowly advancing upper-atmospheric trough, which causes quasi-geostrophic forced ascent, and the orographic support from the Zagros mountain range, the MCS remains quasi-stationary over the next $12 \mathrm{~h}$. Due to the long duration and separation of the up- and downdraught region, the MCS is able to produce an enormous amount of 

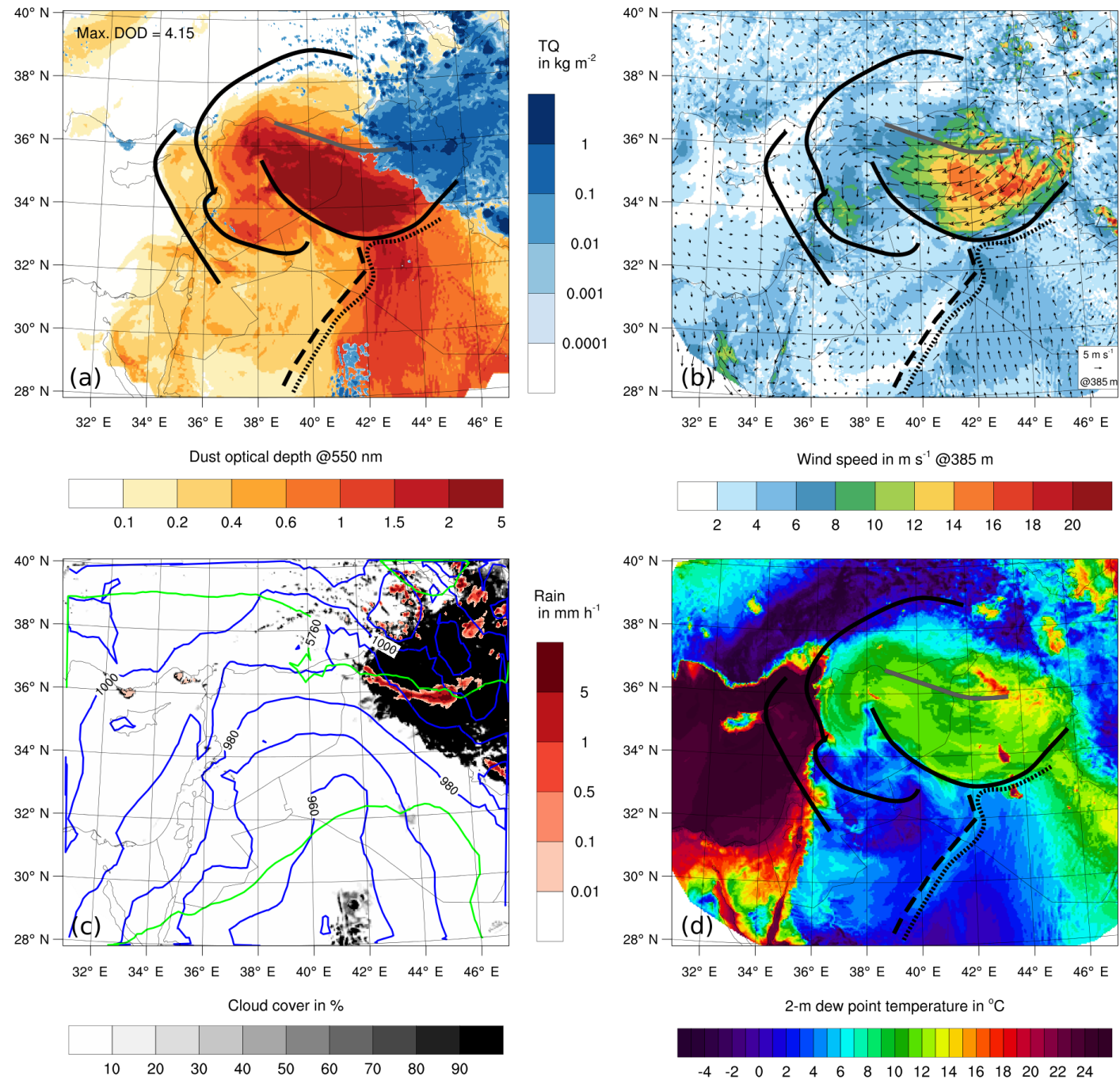

Figure 5. ICON-ART model results at 10:00 UTC, 7 September. Displayed are (a) DOD at 550 nm overlaid with column-integrated hydrometeor content (TQ; cloud water, cloud ice and graupel). (b) wind speed at $385 \mathrm{~m}$ model height and wind velocity as vectors; (c) fractional cloud cover and surface rain rate colour-coded - blue lines show geopotential height of $900 \mathrm{hPa}$ level at 10 gpm intervals, green lines show geopotential height of $500 \mathrm{hPa}$ level at $20 \mathrm{gpm}$ intervals; (d) $2 \mathrm{~m}$ dew point temperature. From west to east solid black lines mark the leading edges of the CPO1, CPO2 and the southern CPO3 boundary. The grey line marks the northern dust plume boundary inside the CPO3. The dashed line marks merged EM inflow front from 5 and 6 September. The dotted line marks the frontal region of inflow from the Persian Gulf.

cool, moist air and a mighty CPO3 downstream of the lineshaped rainfall pattern. During the course of the night, the southerly direction of the $\mathrm{CPO} 3$ is deflected into a westerly flow direction by the RST flow structure and its inflowing air masses. The night-time spread of the $\mathrm{CPO} 3$ towards the west is crucial due to its subsequent interaction with the developing boundary layer mixing during daytime. During nighttime the CPO is confined to a shallow layer of approximately $1 \mathrm{~km}$ close to the surface with wind speeds above $20 \mathrm{~m} \mathrm{~s}^{-1}$ (Figs. A4, A5). Due to the stable stratification, the dust plume does not cover the full CPO depth, and dust concentrations are highest in the lowest hundred metres. With sunrise, downward mixing of momentum increases. This leads to an in- crease in dust emissions and a greater dust plume depth, which subsequently extends throughout the full CPO.

\subsection{Mesoscale convective system and cold-pool outflows}

An in-depth analysis of model results and a comparison to satellite observations is conducted at 10:00 UTC, 7 September (Fig. 5). The simulated MCS has passed its most intensive development stage approximately $4 \mathrm{~h}$ earlier. The main MCS features are still visible, although it is in the stage of dissolution due to the shift of the upper-atmospheric trough towards the east (Fig. 5a). The convection is organized along the orographic features of the Zagros mountain range, exhibiting a sharp line-shaped rainfall distribution. Possibly, 

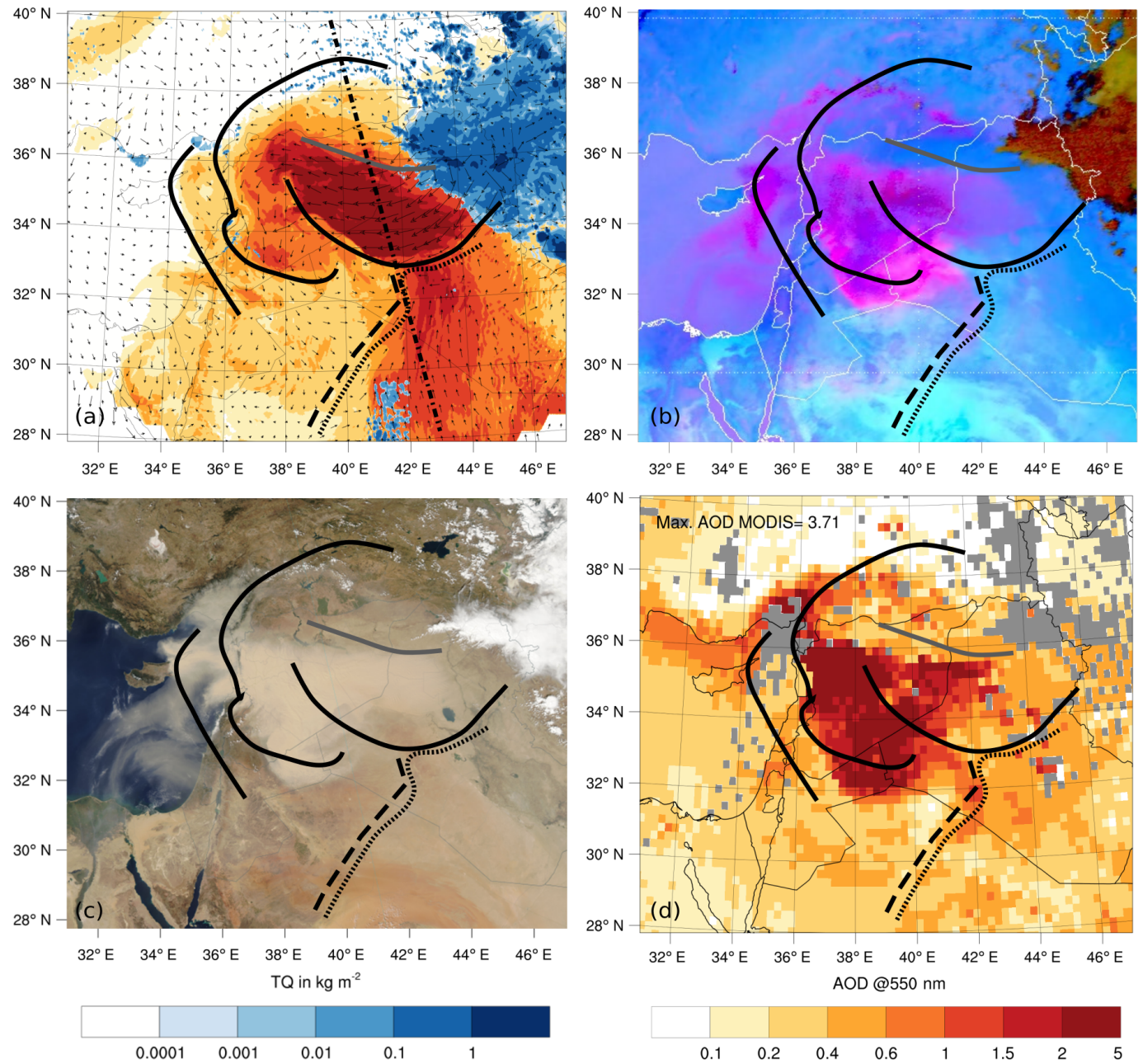

Figure 6. ICON-ART model results and satellite observations for 10:00 UTC on 7 September. Displayed are (a) ICON-ART DOD, columnintegrated hydrometeor content and wind velocity; (b) SEVIRI RGB dust product (Kerkmann et al., 2015); (c) Aqua MODIS VIS satellite image, overpass at 10:35 UTC (NASA Worldview, 2016); (d) Aqua MODIS AOD retrieval using DB2 algorithm (Levy and Hsu, 2015), overpass at 10:35 UTC. The dash-dotted black line marks the CALIPSO ground track at 10:35 UTC.

the convective structure is also shaped by a weak cyclogenesis taking place further east due to the favourable uppertropospheric conditions. The cirrus cloud anvil extends far to the north-east as it is transported away by the upperlevel flow. Downstream of the line-shaped rainfall distribution, near-surface wind speeds increase strongly as the $\mathrm{CPO} 3$ reaches the surface (Fig. 5b). Wind speeds above $12 \mathrm{~m} \mathrm{~s}^{-1}$ are modelled inside the $\mathrm{CPO} 3$ region. The southern edge is distinct and counters the inflow from the Persian Gulf region. The edge is also clearly recognizable in the $2 \mathrm{~m}$ dew point temperature ( $2 \mathrm{~m} \mathrm{DPT}$ ) field which is a good indicator of CPOs due to the change in air mass characteristic (Knippertz et al., 2007). The difference in $2 \mathrm{~m}$ DPT between the $\mathrm{CPO} 3$ and the surrounding air masses is approximately $10 \mathrm{~K}$ (Fig. 5d). Dust has been picked up in large quantities over the previous hours with increasing boundary layer turbulence and DOD values above 2 are modelled in the $\mathrm{CPO} 3$ region
(Fig. 5a). The maximum DOD value is 4.15; it is reached in an area close to the leading edge of the $\mathrm{CPO}$, which shows the highest values of DOD.

Towards the north, the DOD exhibits a sharp gradient (northern boundary of the CPO3 dust plume in Fig. 5). At closer inspection of the wind and dew point temperature fields, it becomes apparent that the decrease in DOD is not linked to the extent of the CPO3 in north-western Syria (Fig. 5b and d). This is due to the orography and the soil type distribution in the region; a change in soil type towards less-emitting light clay and the increase in elevation are responsible for the reduced DOD towards the north. The northern edge of the aged CPO2 is marked by a line of convective clouds over the Taurus mountain range; here a second but less distinct gradient in DOD is visible. In the south-western part of Syria, entering Jordan, the remains of the $\mathrm{CPO} 2$ are also still detectable by an elevated DOD above 1 and higher wind 


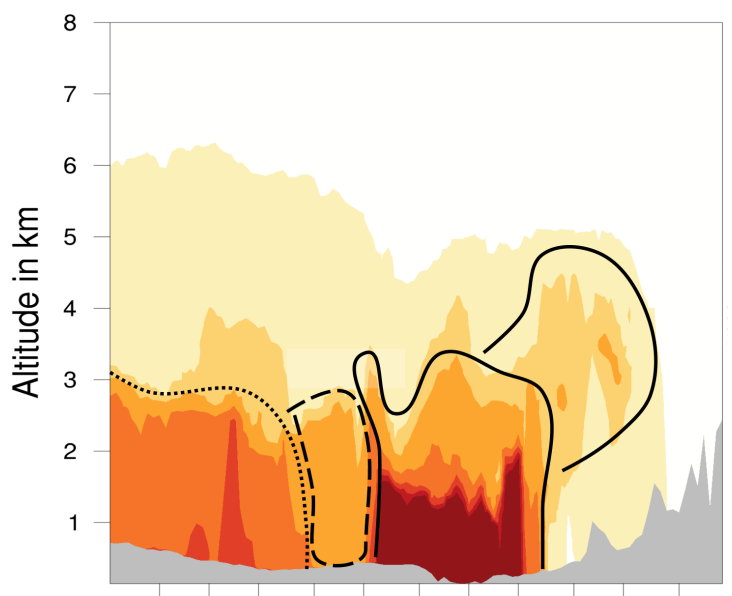

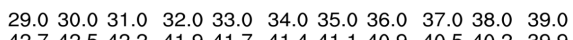

(a)

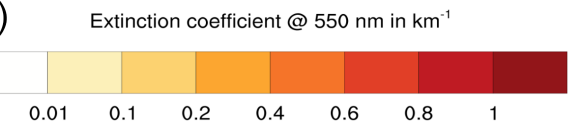

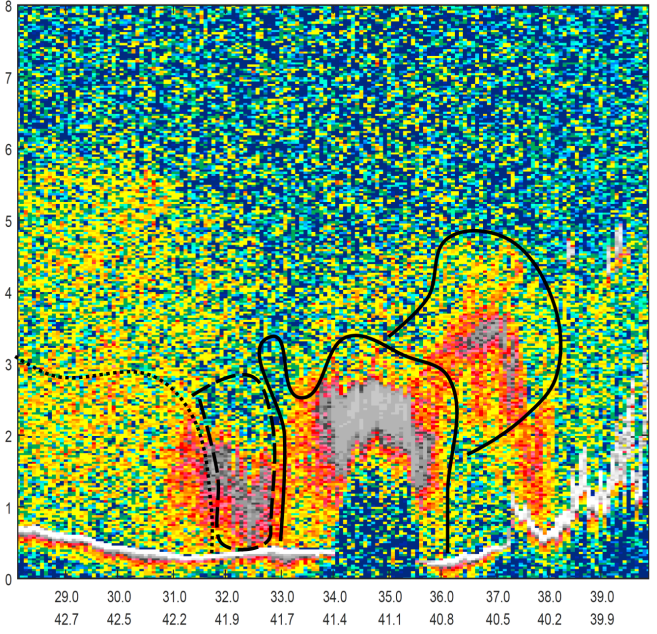

(b)

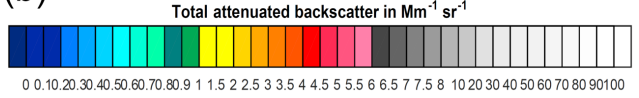

Figure 7. Vertical cross section of ICON-ART model results for 10:00 UTC on 7 September and CALIPSO satellite observations from south to north along the ground track in Fig. 6. (a) ICON-ART mineral dust extinction coefficient. (b) Total attenuated backscatter as measured by CALIOP. No quantitative comparison is possible as two different measures are displayed. The southern dotted black line marks the inflow region from the Persian Gulf. The dashed black line marks the inflow region with EM origin. The southern solid black line marks the CPO3. The northern solid black line marks the aged and lifted CPO2.

speeds up to $10 \mathrm{~m} \mathrm{~s}^{-1}$. In addition, if a closer look is taken, the formation of small convective clouds above the nose of the $\mathrm{CPO} 2$ can be seen in the ICON-ART model results. The aged CPO2 re-intensifies and the arc clouds develop further during the course of the day.

Comparing ICON-ART model results to the corresponding satellite observations shows that all modelled features are confirmed by the observations (Fig. 6). A comparison of the SEVIRI cloud cover with ICON-ART results shows that the cirrus anvil of the MCS has a greater lateral extension in the model, whereas it is confined to around $36^{\circ} \mathrm{N}$ in the observations (Fig. 6b). In addition, the MCS has moved further east by approximately $2^{\circ}$ in reality. Taking the area with the brightest colour as a proxy for the strongest deep-convective area, the MODIS visible satellite image (Fig. 6c) shows good agreement with the line of highest integrated hydrometeor content in ICON-ART (Fig. 6a).

The structure of the MCS determines the shape of the outflow. Therefore, differences in outflow structure can be identified as well. Again, the $\mathrm{CPO} 3$ is more sharply confined between 34 and $36^{\circ} \mathrm{N}$ in the observations, whereas it shows a bow-shaped southward extension beyond $34^{\circ} \mathrm{N}$ in ICON-ART. The northward boundary of the CPO3 is modelled accurately, with a northward deviation at the western tip. There is good agreement in the maximum dust plume optical thickness, with MODIS AOD measurements giving an AOD of 3.71 and the simulation a DOD of 4.15, although again the possible overestimation by MODIS should be kept in mind (Mamouri et al., 2016). Modelled DOD is higher in ICON-ART when compared to MODIS AOD in the eastern part of the $\mathrm{CPO} 3$ and lower in the western part of the $\mathrm{CPO} 3$ (Fig. 6d). Unfortunately, no measurements by MODIS are available over the north-eastern parts of the Mediterranean Sea where a substantial amount of dust is apparent in the visible satellite image. For the eastern part of the $\mathrm{CPO} 3$ the MODIS AOD measurements seem doubtful when comparing to the MODIS visible satellite image.

The aged $\mathrm{CPO} 2$ spreading towards the north is detected by all satellite instruments; it is modelled with an offset towards the north-east by ICON-ART (northernmost solid black line in Fig. 6). Arc clouds forming above the Taurus mountains are noticeable in the simulation and reality. The south-western boundary of the aged $\mathrm{CPO} 2$ is modelled correctly in the Golan Heights region. However, towards the west and south the $\mathrm{CPO} 2$ has advanced further in reality than in the model, as all measurements show a southern edge of the CPO2, which is just about to cross the border into Saudi Arabia. Aerosol optical depths retrieved by MODIS are on the order of 2 , whereas ICON-ART simulates values of around 1. In this case, the MODIS measurements seem more realistic when compared to the visible satellite picture. A possible reason for the underestimation of DOD magnitude in the model is reduced dust emission due to an unrealistic land use characterization. Due to recent changes in the region, an update of the land-use classes can be expected to 
yield significant improvements of modelled DOD magnitude (see Sect. 2) .

The vertical structure of the dust plume can be investigated at this point in time with the help of a CALIPSO overpass which occurred at 10:35 UTC. Results along the flight track are shown from south to north in Fig. 7. The southern inflow region towards the MCS shows high values of the extinction coefficient in ICON-ART and attenuated backscatter in CALIOP (Cloud-Aerosol Lidar with Orthogonal Polarization) measurements. The height of the dust plume is between 5-6 km, with decreasing height towards the MCS. Just south of the main CPO3 dust plume, in a region from 32 to $33^{\circ} \mathrm{N}$, both show a decrease in dust concentrations at upper levels. However, a difference exists in the near-surface values up to $2 \mathrm{~km}$, where CALIOP reports high values of total attenuated backscatter but ICON-ART shows a minimum in extinction coefficient. The reason for this difference becomes clear when looking at the CALIPSO ground track again in Fig. 6. The satellite passes the region where the inflow of EM origin penetrates the RST inflow from the Persian Gulf in a cyclonic rotational movement. The frontal structure is visible in Fig. 5 as a thin line in $2 \mathrm{~m}$ DPT, a gradient in DOD and a change in wind velocity along the front (as can be expected from a frontal structure). ICON-ART is able to simulate the reintensifying EM inflow, thereby enabling the above analysis; however, no dust pickup is connected with the frontal structure. This is due to the less emissive soil type in the region passed by the front. In reality, however, dust was picked up by this frontal structure; this is detectable in all three satellite measurements (Fig. 6). As a result, CALIOP reports high values of attenuated backscatter in this region, whereas ICONART simulates a minimum due to the clean-air characteristics of the EM inflow.

The main CPO3 dust plume is distinct in both figures, with ICON-ART simulating an elevated nose of the CPO3. The differences in CPO3 structure discussed above are identifiable again. ICON-ART simulates a wider and more shallow outflow, whereas in reality it was more confined. In addition, the observations show an approximately $1 \mathrm{~km}$ higher main dust plume compared to ICON-ART. Altitudes below $2 \mathrm{~km}$ are marked as no-signal regions in the CALIPSO feature mask due to the attenuation of the lidar signal (not shown). On the northern side of the plume beyond $36^{\circ} \mathrm{N}$, a minimum captured by both is visible, once more illustrating the wellsimulated northern boundary of the CPO3 in this region. Further towards the north, the overarching dust plume structure consisting of dust picked up by the aged CPO2 is represented very similarly in simulation and measurement.

In summary, a northward deviation of the flow structure in ICON-ART can be identified both for the CPO2 and the $\mathrm{CPO} 3$ although the overall intensity and characteristics are simulated well. The combination of the northern deviation towards less dust-emitting soil types and the wider, less welldefined main outflow region reduces the amount of DOD over western Syria due to a less intense channelling of the
CPO3. Furthermore, the re-intensification of the aged CPO2 is modelled by ICON-ART; however, it was observed with greater magnitude in reality. The reduced amount of dust in the atmosphere in ICON-ART leads to a reduction in longrange transport of dust towards the EM over night.

When comparing our results to those of Solomos et al. (2017, their Fig. 10), again large differences become apparent, especially in the spatial structure of the dust plume. This is the result of the interaction of multiple, consecutive CPOs in our simulation. In addition, in ICON-ART, strongest winds and largest dust emission are modelled within the CPOs and not along the outflow boundaries.

\subsection{Long-range transport to the Eastern Mediterranean}

From 10:00 UTC onwards on 7 September, the MCS starts to dissipate and is, in the course of this, advected east along with the mean flow conditions above $500 \mathrm{hPa}$. The dust transport to the EM is complex; the previously identified plumes are advected in different directions at different altitudes, as visible in the SEVIRI RGB dust product animation (Kerkmann et al., 2015). This results in the multilayered plume structure observed by Mamouri et al. (2016). The aged plume from the CPO1 and HL is transported south-westward during the course of 7 September; consequently dust is detectable in Israel on 7 September already. The CPO3 air mass created during the night spreads south-west during daytime on 7 September. At all times, it shows the characteristic features associated with CPOs, such as an increase in surface wind speed, higher dew point temperatures and an arc cloud forming above the leading edge during the afternoon hours. The high surface wind speeds and turbulent mixing inside the $\mathrm{CPO} 3$ result in enormous dust emissions of more than $10 \mathrm{~g} \mathrm{~m}^{-2}$ during daytime. Maximum dust concentrations inside the main dust plume reach extraordinary values above $10000 \mu \mathrm{g} \mathrm{m}^{-3}$ in large areas and the dust is transported within the full boundary layer height up to $5 \mathrm{~km}$ (Figs. A4, A5).

With nightfall on 7 September the CPO2 and CPO3 merge. As the merged CPO is still located in the western, downstream flank of the RST, the air mass and dust contained within it are advected fast towards the south-west over the course of the night. The Dead Sea Rift Valley is passed by the dust mass after midnight on 8 September, with the dust plume interacting with the complex orography. A comparison of simulated DOD with satellite observations for 11:00 UTC, 8 September, shows that the model represents the observed dust plume structure in the northern part of the EM (Fig. A6). In this region, ICON-ART DOD values are up to 1 order of magnitude higher and show better spatial agreement than operational dust forecasts (see Sect. 1) at a longer forecast time. The highest dust concentrations are present between Cyprus and Syria, although the dust plume has advanced approximately $2^{\circ}$ further west in observations, reaching Cyprus. This 
shift can be explained by the northward deviation and less intense channelling of the $\mathrm{CPO} 3$ as well as the long forecast time.

For the dust concentration, a strong gradient on small spatial scales exists in the region of Cyprus. On 8 September Mamouri et al. (2016) report mean daily $\mathrm{PM}_{10}$ values of $2900 \mu \mathrm{g} \mathrm{m}^{-3}$ in Larnaca, $1500 \mu \mathrm{g} \mathrm{m}^{-3}$ in Limassol and $500 \mathrm{\mu g} \mathrm{m}^{-3}$ in Paphos, located approximately $70 \mathrm{~km}$ away from each other from east to west along the southern Cyprus coast. A similar decrease from east to west is detectable in AOD measurements analysed by Mamouri et al. (2016); Larnaca shows the highest values, followed by Limassol and then Paphos. Due to this strong gradient and as the modelled dust plume does not reach Cyprus, a direct comparison of model results to observations in Cyprus is not meaningful, as, in order to infer properties of the dust plume, the same air masses need to be compared. Therefore, a comparison with lidar observations in Limassol, Cyprus, by Mamouri et al. (2016) is conducted at the $2^{\circ}$ longitudinal offset observed between the model and observations as discussed above. Taking into account the $2^{\circ}$ longitudinal offset in ICON-ART, the vertical structure of the dust plume arrival in fact does reproduce observations by Mamouri et al. (2016). The arrival of two distinct dust plumes is detectable and also noted by Mamouri et al. (2016), confirming the complex evolution process of the dust event (Fig. A7). A first elevated plume extending from 1.5 to $4 \mathrm{~km}$ is noticeable on 7 September between 09:00 and 18:00 UTC in the model results, it is modelled with concentrations up to $1000 \mu \mathrm{g} \mathrm{m}^{-3}$. This agrees with observations by Mamouri et al. (2016), who report a first thick dust layer crossing Cyprus between 2 and $3.7 \mathrm{~km}$ height on the evening of 7 September. Mamouri et al. (2016) observe the arrival of the main dust plume past 19:00 UTC, 7 September, with concentrations of up to $2000 \mu \mathrm{g} \mathrm{m}^{-3}$ at $0.75-1.5 \mathrm{~km}$ height. ICON-ART shows the main dust plume arrival past 21:00 UTC, 7 September, with concentrations of up to $3000 \mu \mathrm{g} \mathrm{m}^{-3}$ at $0.5-2 \mathrm{~km}$ height. On 8 September, dust concentrations increase up to $3500 \mu \mathrm{g} \mathrm{m}^{-3}$ and the plume thickness grows further, extending from $0.5 \mathrm{~km}$ up to $3 \mathrm{~km}$ height in the model. Due to the $2^{\circ}$ longitudinal shift, the ICON-ART profile is located over the sea. Therefore, little downward mixing of dust occurs on 8 September, as landinduced boundary layer mixing is missing. Consequently, the near-surface concentrations do not reach the values reported by Mamouri et al. (2016) for Cyprus.

Dust transport into the southern EM is not simulated with the correct magnitude by ICON-ART despite the overall dust plume structure being captured, even when accounting for the MODIS AOD retrieval bias (Mamouri et al., 2016). MODIS measures AOD values that were consistently between 2 and 4 over land and values above 5 over sea in the southern EM. In this area, the contribution of the different plumes transported into the region along the Mediterranean coast from the north and across the Dead Sea Rift Valley from the north-east is especially complex due to the steep orog- raphy. Therefore, the transport into this region is analysed further in Sect. 3.4.1 in order to investigate the differences found.

Overall, a significant dust forecast improvement is achieved through convection-permitting simulations with ICON-ART at $47 \mathrm{~h}$ forecast time. During daytime on 8 September the dust plume is mostly stationary in the EM and influenced by the local circulation systems. In visible satellite pictures, the dust can be seen to remain in the EM at high concentrations over the course of the next 4 days. This period is not investigated as a part of this study as the scope of this work is the analysis of the generating mechanisms.

Due to the problems in simulating dust transport towards the southern EM with the correct magnitude, the next section investigates the timing and structure of the dust plume and CPO arrival in Israel in reality and simulation.

\subsubsection{Environmental station data}

In this section the simulated dust concentrations are compared to measurements from three stations in Israel. The selected stations are Afula, Jerusalem (Bar Ilan) and BeerSheva for $\mathrm{PM}_{10}$ measurements, as well as Sedé Boqer AERONET for AOD comparison (see Fig. 9c for a map of the station locations).

The stations all show individual dust concentration characteristics during the event, and the discussed features are present at other stations with similar characteristics as well. Beer-Sheva is chosen for its close proximity to Sedé Boqer at $45 \mathrm{~km}$ distance, in a similar arid desert environment. Clearly four stations are not enough for a complete validation of the complex dust distribution in the region. The comparison shown here is meant to highlight differences between the model and reality as well as to investigate dust transport features.

Due to its northern location the modelled main dust plume reaches Afula first at 00:00 UTC, 8 September. Here, the highest values of DOD of up to 1.5 are modelled (Fig. 8a). A few hours later, Jerusalem shows an increase and its peak optical depth. Even later, DOD increases in Sedé Boqer due to its location in the south of Israel, but the DOD values reach higher levels than in Jerusalem. Possibly, this is due to the lower altitude of the station as well as due to local dust emission.

A comparison of modelled DOD and AERONET AOD measurements shows a similar development of the optical depth for 7 September, although with an offset of 0.3. The offset is explainable by AERONET measuring the optical depth due to all aerosol species, whereas we only display DOD from ICON-ART, as well as a possible underestimation of dust background concentration in the model. Nevertheless, the main signal appears to be shaped by mineral dust processes captured by ICON-ART. The maximum modelled DOD for Sedé Boqer is 1.0 on 8 September, compared to 4.1 measured by AERONET. MODIS is in good agreement with 


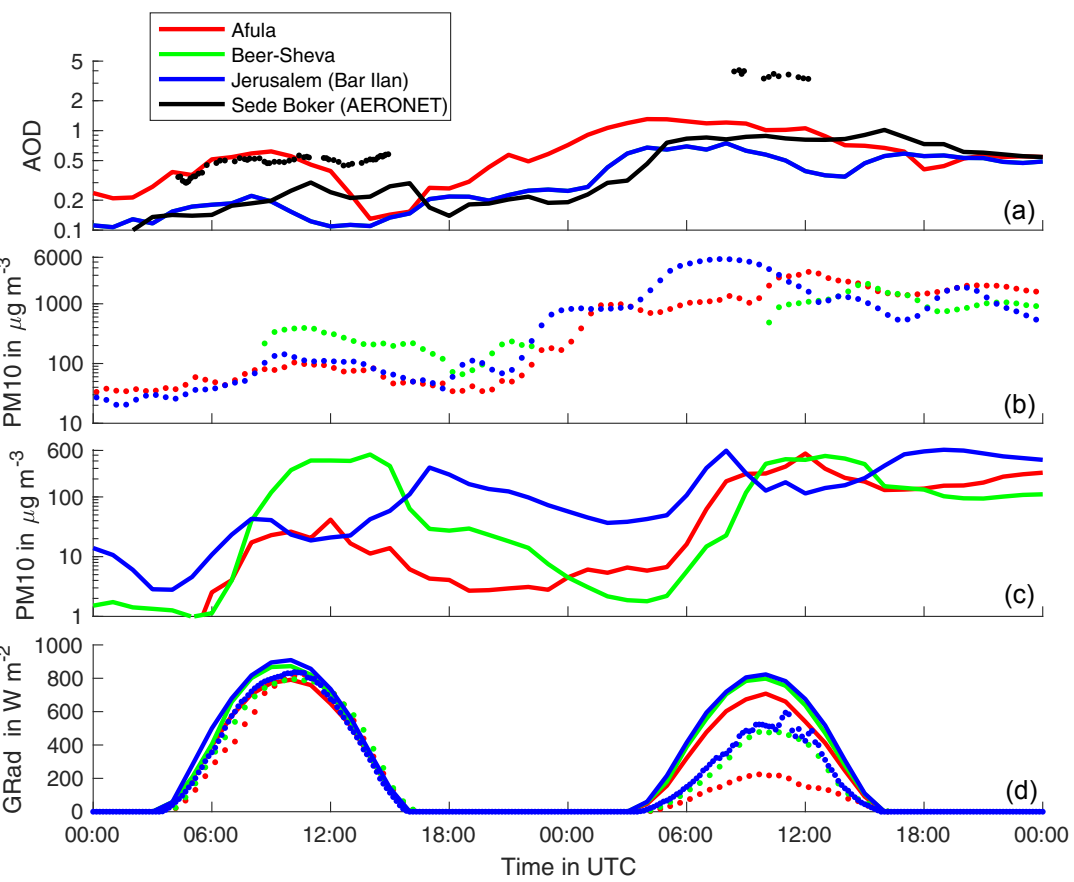

Figure 8. Observations and model results for three stations in Israel for 7 and 8 September. Points denote observations, and solid lines denote model results. Please note the logarithmic $y$-axis scaling, which differs by a factor of 10 between the second and third sub-plot. Shown are (a) modelled DOD and AERONET measurements for Sedé Boqer; (b) measured PM 10 concentrations; (c) modelled PM 10 concentrations; (d) global radiation (GRad) - the values shown are for Afula, Beer-Sheva and Jerusalem due to data availability.

the AERONET measurements. Therefore, we assume that the AERONET measurements are representative for a larger region. Thus, ICON-ART shows an underestimation of DOD by a factor of 4 .

When comparing $\mathrm{PM}_{10}$ measurements, a larger difference between model results and observations on the order of 1 order of magnitude becomes apparent. The large differences in absolute values of modelled and measured $\mathrm{PM}_{10}$ concentrations (Fig. $8 \mathrm{~b}$ and c) are probably linked to the underestimation of dust transport in connection with the $\mathrm{CPO} 2$, possibly due to an out-of-date description of soil properties in Mesopotamia (see Sects. 2 and 3.3). Furthermore, there is an inadequately modelled interaction of the dust plume with the complex orography of the Dead Sea Rift Valley as the next section shows.

Despite the large difference in absolute values, some insight into dust transport processes can be gained by comparing the course of the measured and modelled $\mathrm{PM}_{10}$ concentrations. The DOD in Afula reaches highest values during the night from 7 to 8 September, and $\mathrm{PM}_{10}$ measurements show a corresponding increase of up to $985 \mu \mathrm{g} \mathrm{m}^{-3}$, which is missed by ICON-ART. A second, higher peak in concentrations with values of up to $3422 \mu \mathrm{g} \mathrm{m}^{-3}$ is measured after noon on 8 September in Afula at $57 \mathrm{~m}$ surface elevation. This is linked to the onset of turbulent mixing needed to transport the highest dust concentrations from $1 \mathrm{~km}$ dust plume height towards the surface. The downward mixing of dust leading to the second, higher maximum is captured by ICON-ART, as the results show a similar shape of the $\mathrm{PM}_{10}$ concentrations curve compared to the measurements with a peak at 12:00 UTC at $532 \mu \mathrm{g} \mathrm{m}^{-3}$.

Highest overall $\mathrm{PM}_{10}$ concentrations are measured by the Jerusalem station with $5607 \mu \mathrm{g} \mathrm{m}^{-3}$. The main peak is the earliest and most pronounced peak of all stations at 08:00 UTC, 8 September. This is also the case in ICON-ART, although with a shorter peak duration and at $615 \mu \mathrm{g} \mathrm{m}^{-3}, 1$ order of magnitude too low. The earlier and higher peak concentrations in Jerusalem are to due to the elevated location of the measurement station at $770 \mathrm{~m}$, which is almost inside the dust plume. For this reason, $\mathrm{PM}_{10}$ concentrations are also more correlated with the shape of the DOD curve at this station. A secondary peak after sunset is visible in the measurements and model results.

$\mathrm{PM}_{10}$ measurements in Beer-Sheva already show a first, pronounced peak on 7 September, despite low values of AOD in Sedé Boqer. The first maximum is captured in magnitude and temporal duration by ICON-ART and can be linked to local dust emission. No measurements are available during the night, but on 8 September Beer-Sheva measured a maximum dust concentration of $2155 \mu \mathrm{g} \mathrm{m}^{-3}$, compared to $512 \mu \mathrm{g} \mathrm{m}^{-3}$ modelled by ICON-ART. Therefore, both the AERONET measurements in Sedé Boqer and the $\mathrm{PM}_{10}$ measurements in Beer-Sheva show an underestimation by a factor of 4 of the amount of dust in the model. 

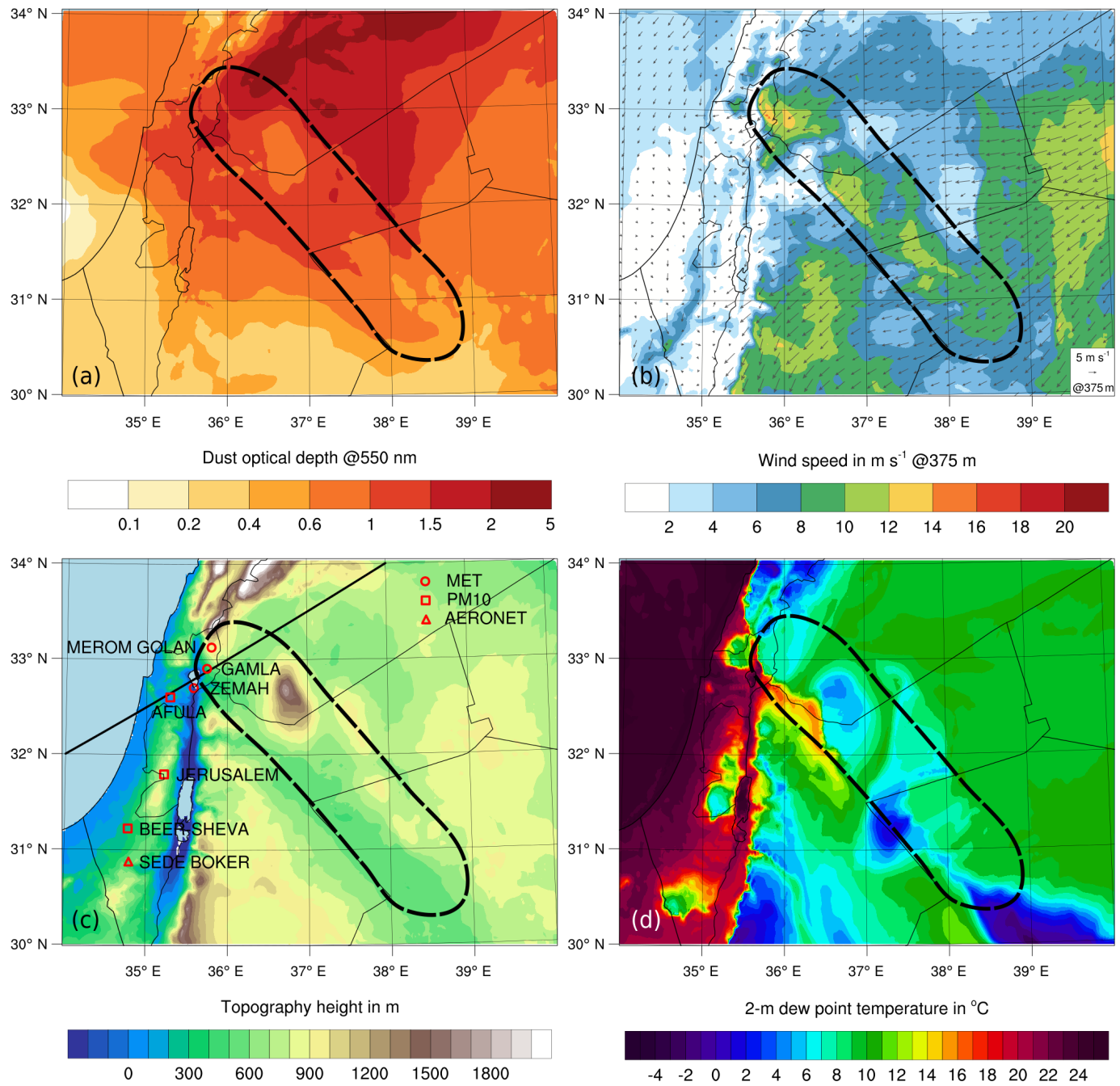

Figure 9. ICON-ART model results at 03:00 UTC, 8 September. Displayed are (a) DOD at $550 \mathrm{~nm}$; (b) wind speed at $375 \mathrm{~m}$ model height and wind velocity as vectors; (c) the orography in the region (colour-coded); (d) $2 \mathrm{~m}$ dew point temperature. The dashed black line marks the region where supercritical flow conditions and the subsequent hydraulic jump occur. The solid black line in (c) shows the location of the ICON-ART vertical transect displayed in Fig. 10. In addition, the location and the names of stations used for comparison of results are given.

ICON-ART fails to reproduce the measured low values of global radiation because for the radiative impact, the absolute values of the dust concentration are of importance. The differences visible in the DOD above the stations manifest themselves in differences between the modelled amount of global radiation at the stations.

\subsubsection{Hydraulic jump upstream of the Dead Sea Rift Valley}

In order to understand the problems of the model to forecast dust in Israel with the correct magnitude the transport processes upstream have to be investigated in more detail.

In Fig. 10, a cross section of ICON-ART results along a cross section through the Golan Heights is displayed for 03:00 UTC, 8 September. The location of the cross section and corresponding meteorological situation is illustrated in Fig. 9. The arrival of the dust plume is simulated above a height of $1 \mathrm{~km}$ in Israel. This is in good agreement with measurements of the dust plume height in Israel, which also report an arrival of the dust plume at $1 \mathrm{~km}$ height (Alpert et al., 2016).

There is a remarkable wave structure in the extinction coefficient on the lee side of the Golan Heights (Fig. 10). In the region of the wave structure, after passing the Golan Heights crest, the vertical depth of the dust plume decreases significantly to a few hundred metres. The plume expands and returns to its original height again in an abrupt expansion further to the west, which is accompanied by a sharp decrease in flow speed. The reason for this behaviour is the existence of a flow phenomenon termed "hydraulic jump". 


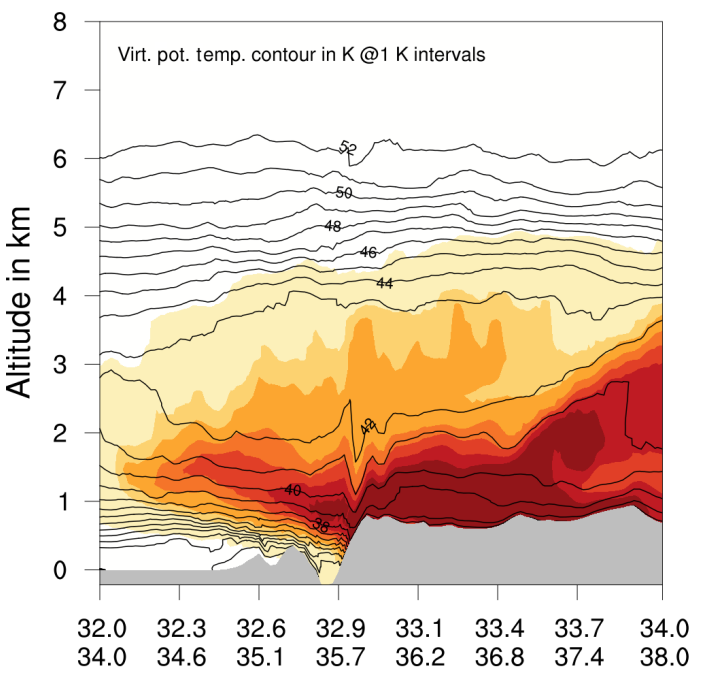

(a) Extinction coefficient @550 $\mathrm{nm}$ in $\mathrm{km}^{-1}$

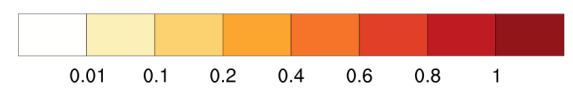

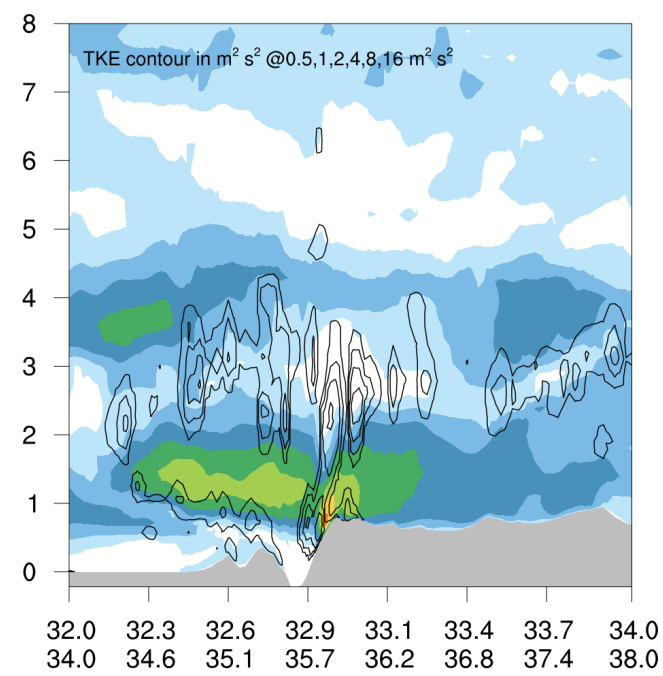

(b) Wind speed in $\mathrm{m} \mathrm{s}^{-1}$

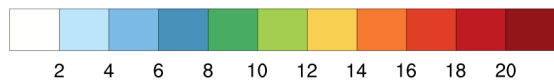

Figure 10. ICON-ART model results along a vertical cross section from $32^{\circ} \mathrm{N}, 34^{\circ} \mathrm{E}$ to $34^{\circ} \mathrm{N}, 38^{\circ} \mathrm{E}$ at $03: 00$ UTC, 8 September. Displayed in panel (a) is the colour-coded extinction coefficient overlaid with virtual potential temperature contours. In panel (b) wind-speed is colourcoded and overlaid with turbulent kinetic energy contours.

Hydraulic jumps are connected to flows going from a subcritical flow stage with Froude numbers $F r$ smaller than 1 to a supercritical flow stage, with Froude numbers greater than 1. According to Drobinski et al. (2001) the Froude number can be calculated as

$F r=\frac{U}{\sqrt{g h}} \cdot \sqrt{\frac{\Theta_{v}}{\Delta \Theta_{v}}}$.

Here, $U$ denotes the wind speed and $\Theta_{v}$ the virtual potential temperature in the atmospheric boundary layer, chosen at a representative level, and $\Delta \Theta_{v}$ denotes the temperature inversion at the boundary layer top. Further, $g$ is the gravitational acceleration and $h$ the atmospheric boundary layer height.

Hydraulic jumps have been documented penetrating the Dead Sea valley for flow conditions from the west (Metzger, 2016). The flow across the Golan Heights shows characteristic features of a supercritical flow with a subsequent hydraulic jump (see Fig. 10). These are

1. a continuous decrease in mixing layer height detectable in the virtual potential temperature and extinction coefficient fields leading to compression of the subcritical flow from east to west.

2. a sharp decrease in the vertical flow depth, connected to a rise in flow speed, after passing the orographic Golan Heights crest. This denotes the transformation of the flow state from sub- to supercritical.

3. a subsequent sudden increase in flow depth when the flow state reverts to the subcritical stage again inside the
Dead Sea Rift Valley. This is accompanied by a sharp decrease in flow speed and connected to an increase in atmospheric turbulence.

An approximate calculation of the Froude number upstream and downstream of the Golan Heights crest height with average flow conditions as simulated by ICON-ART confirms the conversion of the flow state:

$$
\begin{aligned}
& F r_{\text {upstream }}=\frac{8 \mathrm{~m} \mathrm{~s}^{-1}}{\sqrt{9.8 \mathrm{~m} \mathrm{~s}^{-2} \cdot 1200 \mathrm{~m}}} \cdot \sqrt{\frac{312 \mathrm{~K}}{2 \mathrm{~K}}}=0.9, \\
& F r_{\text {downstream }}=\frac{12 \mathrm{~m} \mathrm{~s}^{-1}}{\sqrt{9.8 \mathrm{~m} \mathrm{~s}^{-2} \cdot 800 \mathrm{~m}}} \cdot \sqrt{\frac{313 \mathrm{~K}}{2 \mathrm{~K}}}=1.7 .
\end{aligned}
$$

Hydraulic jumps have been investigated and suggested as dust-generating mechanisms (Cuesta et al., 2009). Their existence and interaction with the orography under strong easterly flow conditions has been proven for the Sahara (Drobinski et al., 2009). As the gust front of the $\mathrm{CPO} 3$ reaches the Dead Sea Rift Valley almost along its full length, the flow reaches supercritical stage in the vicinity of many prominent orographic features (Fig. 9b). Consequently, the widespread existence of hydraulic jumps in connection with the upstream supercritical flow is assumed to be responsible for dust emissions on the eastern side of the Dead Sea Rift Valley. Dust emission in the region is assisted by the timing of the event, as in September the soil in the region is most erodible due to the preceding hot and dry summer. Differentiating between local and remote dust production, Kishcha et al. (2016) show that the former can indeed contribute significantly in the 

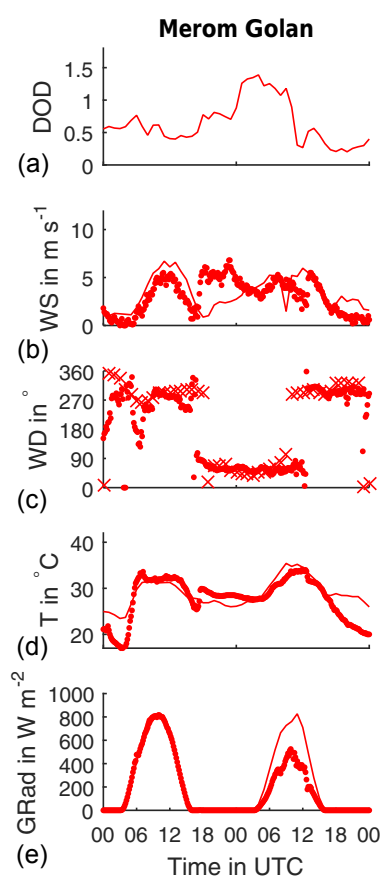
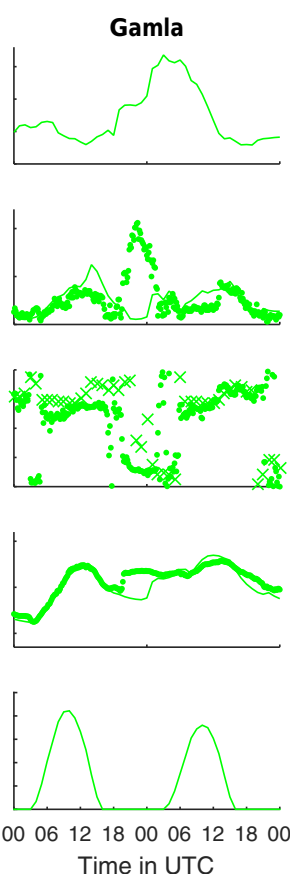
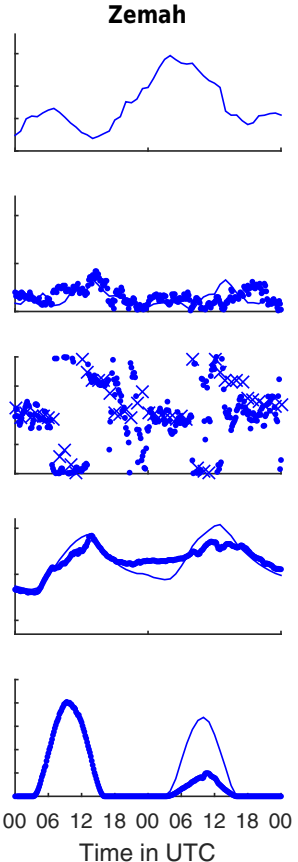

Figure 11. Observations and model results for three stations in the Golan Heights for 7 and 8 September. Points denote observations and solid lines/crosses model results. From top to bottom: (a) modelled DOD; (b) wind speed (WS); (c) wind direction (WD); (c) $2 \mathrm{~m}$ surface temperature; (e) global radiation (GRad).

Dead Sea Rift Valley. Crouvi et al. (2017) stress the importance of local dust emission in the Negev for the case of a local haboob in Israel, generated by the penetrating sea breeze in combination with synoptic-scale drivers.

The existence of hydraulic jumps is modelled by ICONART and detectable along many cross sections and at different times in the region. Some of them occur on the lee side of much less pronounced orographic features such as the mountain structure visible at $33.5^{\circ} \mathrm{N}, 37.0^{\circ} \mathrm{E}$ in Fig. 10. Although ICON-ART simulates the flow phenomena, the location and magnitude of the hydraulic jumps need to be validated in order to evaluate the simulation quality.

\subsubsection{Meteorological station measurements}

The validation is done with the help of three meteorological stations approximately along the model cross section through the Golan Heights. The locations and names of the stations used are marked in Fig. 9c. Unfortunately, no measurements are available in Jordan, where the existence of the hydraulic jumps is detectable in many places in ICON-ART and where the more erodible state of the soil is assumed to be responsible for high dust emissions.

The measurements of three meteorological stations are displayed together with the respective model results for their location in Fig. 11. The arrival of the main dust plume is simulated by ICON-ART past 18:00 UTC on 7 September.
Subsequently, DOD values above 1.5 are reached during the night.

The development of the supercritical flow regime penetrating the Dead Sea Rift Valley is observed at two meteorological stations. It is detectable by marked, high wind speeds, a change in wind direction towards east and a sudden increase in temperature by approximately $4^{\circ} \mathrm{C}$. The higher Merom Golan station is first affected shortly before 18:00 UTC, whereas the lower Gamla station experiences high wind speeds only from 20:00 UTC onwards. Interestingly, confirming the supercritical flow theory, the highest values of wind speed are measured in Gamla around midnight. This is because the flow has more potential for gravitational acceleration from Merom Golan at $950 \mathrm{~m}$ elevation down to Gamla at $405 \mathrm{~m}$ elevation above sea level. Zemah, the station at the bottom of the Dead Sea Rift Valley at $-200 \mathrm{~m}$ neither reports high wind speeds nor a change in wind direction at any point during the night as the supercritical flow does not reach the valley bottom.

The magnitude and timing of the supercritical flow regime is not captured correctly by ICON-ART, as a comparison of observations with model results shows. Although model results for Merom Golan show an increase in wind speed and a change in wind direction, the results are far from the observed intensity and $2 \mathrm{~h}$ late. For the lower Gamla station ICON-ART simulates the arrival of the supercritical flow with a delay of $6 \mathrm{~h}$ and only a third of the observed intensity. As in the observations, the arrival is detectable in changes in 
wind speed, direction and surface temperature. The Zemah station and valley floor remains unaffected in ICON-ART as in reality. The possible reasons for the deviation of the simulation from reality include an unrealistic night-time boundary layer regime, incorrect atmospheric conditions upstream of the valley and a delayed arrival of the CPO3. As a result, possible mineral dust emissions due to the supercritical flow cannot be captured by ICON-ART. Through its destabilizing night-time boundary layer effect, mineral dust itself can provide a positive feedback mechanism to higher near-surface wind speeds and again higher dust emissions in the supercritical flow region. This is visible in the Zemah measurements, where the observations show much higher night-time surface temperature values than the model. As there is a reduced amount of dust in ICON-ART compared to reality, it underestimates the mineral dust radiative night-time warming effect.

As a result of the underestimated dust concentrations, ICON-ART is unable to capture the correct magnitude of reduction in global radiation due to mineral dust during the daytime. Reductions in maximum global radiation for Zemah are modelled to be $125 \mathrm{~W} \mathrm{~m}^{-2}$, whereas in reality $611 \mathrm{~W} \mathrm{~m}^{-2}$ were observed between 7 and 8 September.

In summary, the existence of supercritical flow conditions in the region with connected hydraulic jumps is assumed to cause widespread and strong dust emissions on the eastern side of the Dead Sea Rift Valley. This contributes to the exceptional amount of dust in the southern part of the EM on 8 September. ICON-ART captures the special flow phenomena, albeit not with the correct magnitude and timing. The lack of a sufficiently developed supercritical flow and resulting high near-surface wind speeds prevents dust emission in Jordan and Israel in the model.

In combination with already underestimated dust emissions due to the recent land cover changes and soil degradation in the Mesopotamia region (see Sects. 2 and 3.3), this provides an explanation why dust transport into the southern EM is underestimated by 1 order of magnitude. Nevertheless, ICON-ART provides a detailed understanding of previously unknown processes contributing to the historic dust event, which makes these findings worth reporting.

\subsection{Mineral dust radiative effect}

The validation of the mineral dust distribution and transport characteristics with satellite and station measurements show overall good agreement between ICON-ART and the observations, especially during the early stages of the event. The simulation therefore allows the investigation of the mineral dust radiative effect. Using ICON-ART, the radiative effect of mineral dust can be studied in detail through the differences between the simulation including mineral dust radiation interaction (ARI) and without it (CTRL). An analysis of the mineral dust radiative effect on surface conditions is conducted at two characteristic points in time during the dust storm development.

The first analysis is performed at 03:00 UTC, 7 September, as it shows interesting night-time features due to mineral dust (Fig. 12). The point in time chosen is just before sunrise in the region. The mineral-dust-affected areas show the expected behaviour in terms of its influence on radiative transfer. Net global radiation at night is increased by values between 5 and $50 \mathrm{~W} \mathrm{~m}^{-2}$, with higher values in regions with higher aerosol optical thickness (Fig. 12d). The increase is caused by an increase in downwelling longwave atmospheric radiation (not shown). Consequently, the amount of energy radiated into space is reduced, which causes a night-time warming of the surface. The reductions in net global radiation towards the east are caused by the daytime effect of mineral dust, as the sun is rising in this region already. The $2 \mathrm{~m}$ temperature field outside the CPO3 and MCS region (which themselves are discussed further below) shows the expected behaviour for mineral dust at night with an increase in surface temperature for ARI (Fig. 12c). Also visible are smallerscale irregularities showing local temperature differences located outside the region affected by mineral dust. These are introduced due to the slightly different location and timing of convection in both runs.

The magnitude of the temperature response to mineral dust radiative forcing is large when compared to other studies with values of up to $5 \mathrm{~K}$ (Tegen et al., 2006; Highwood and Ryder, 2014; Rémy et al., 2015). A possible explanation are the high values used for the imaginary part of the mineral dust refractive index in the near-infrared spectral region, making the dust more absorptive. No homogeneously increased emissions are observed despite the decreased vertical stability outside the CPO3 area (Fig. 12b). The DOD is lower by more than 0.1 for most regions in the ARI run, although the maxima between runs are similar. This results from the decreased emission on the previous day with a more stable boundary layer during daytime (not shown).

The DOD difference shows regions with an increased DOD at the leading edges of the CPOs in ARI (Fig. 12a). As the overall maxima of DOD are of comparable magnitude in ARI and CTRL, this can be attributed to a different propagation speed of the CPOs between runs. The CPOs in the ARI run show a higher propagation speed, which is not only detectable in the DOD but also in the wind speed and $2 \mathrm{~m}$ DPT signal, especially at later stages (not shown). In ARI, the CPO with its steep DOD gradient arrives earlier compared to CTRL. Therefore, a higher DOD is shown in the leading-edge region at the same point in time. Furthermore, the leading edge is more sharply defined in the ARI simulation in general (not shown). The difference in DOD goes hand in hand with differences in dust emission, which are also apparent in Fig. 12.

Inside the $\mathrm{CPO} 3$ region, a $2 \mathrm{~m}$ temperature cooling of more than $2 \mathrm{~K}$ can be observed for ARI (Fig. 12c). This is the opposite of the expected mineral dust night-time effect as dis- 

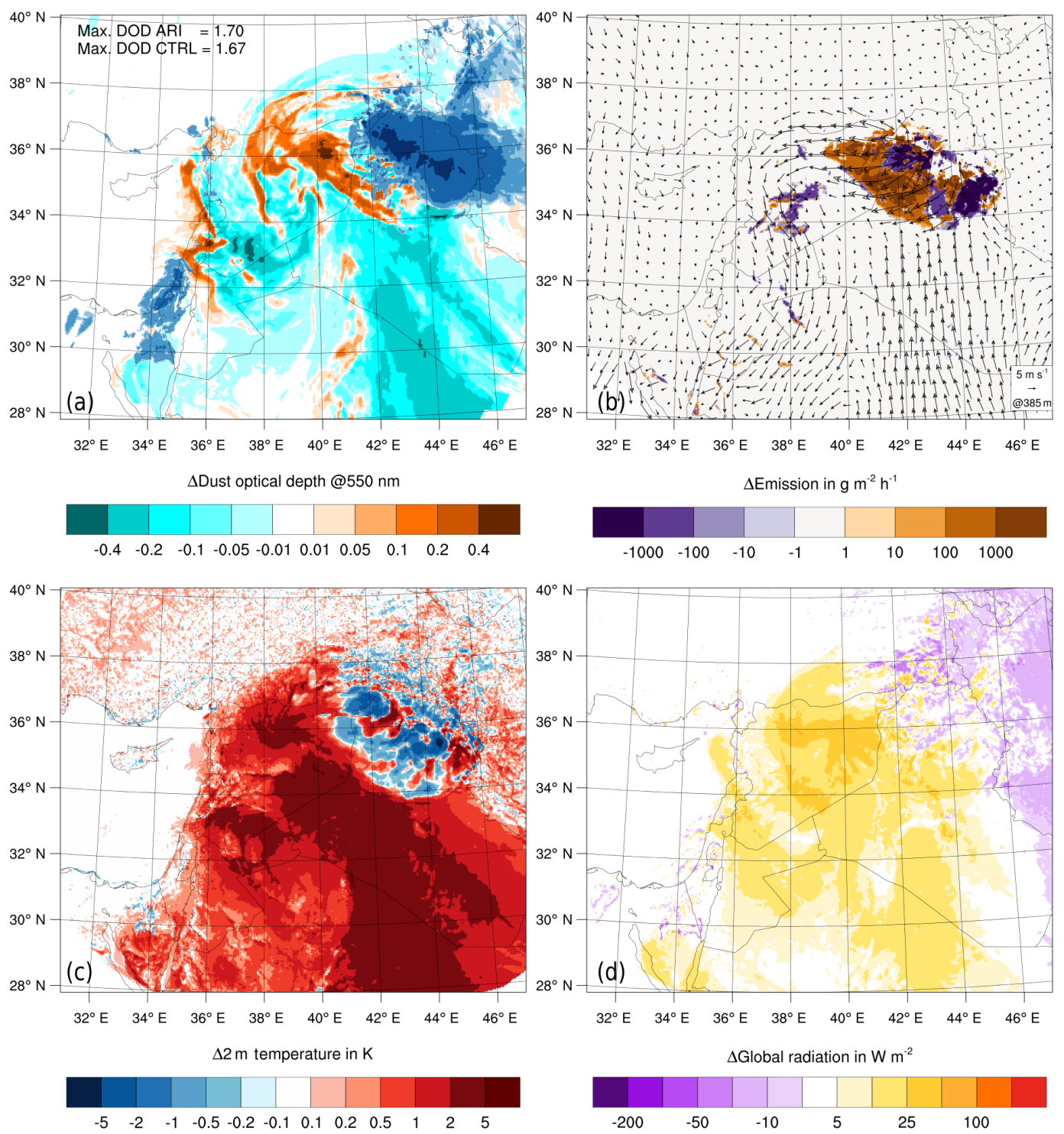

Figure 12. ICON-ART model results at 03:00 UTC, 7 September. All results show ARI-CTRL. Displayed are (a) column-integrated hydrometeor content as in Fig. 5 and difference in DOD; (b) wind velocity and difference in hourly mineral dust emission; (c) difference in $2 \mathrm{~m}$ temperature; (d) difference in net global radiation at the surface.

cussed above. However, the mineral dust radiative forcing in this region remains positive (Fig. 12d). Dust emission increases in the ARI run despite a cooler surface, which again is not expected. All findings point towards a more intense $\mathrm{CPO} 3$ in the ARI run, which can explain all of the above observations.

A more intense and faster spreading CPO can have multiple reasons, and further research is necessary in order to quantify the different contributions. The reasons may be the following:

1. more intense convection leading to more rainfall which can evaporate, this in turn cooling the $\mathrm{CPO}$ more. The intensity of the convection can be increased due to a warmer inflowing air mass because of the mineral dust radiative surface heating at night.

2. more potential for evaporation due to a warmer surface boundary layer, also creating a cooler CPO.

3. a more stable stratified and thereby less turbulent CPO, preventing the loss of energy due to turbulent friction.

4. travel of the CPO into a less stable night-time boundary layer due to mineral dust radiative surface heating. Therefore, less potential and kinetic energy of the CPO needs to be invested in order to lift the stable night-time boundary layer in front. Due to the reduced resistance, propagation speed can increase. 


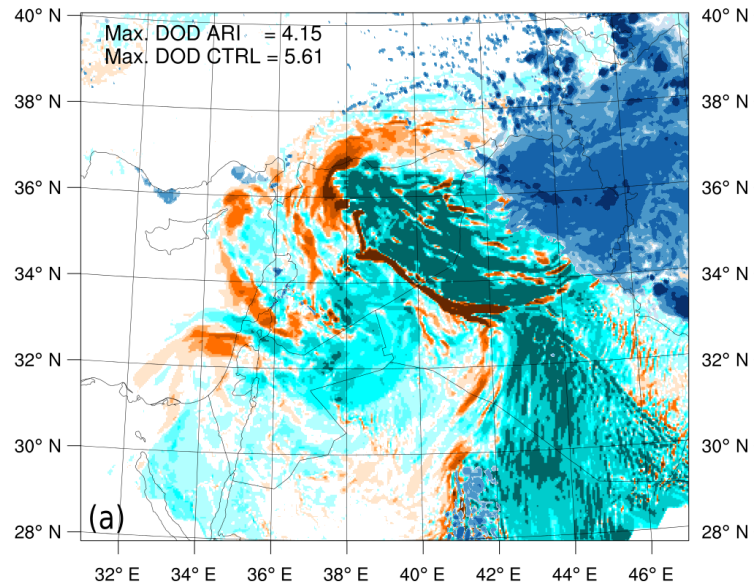

$\Delta$ Dust optical depth @550 nm
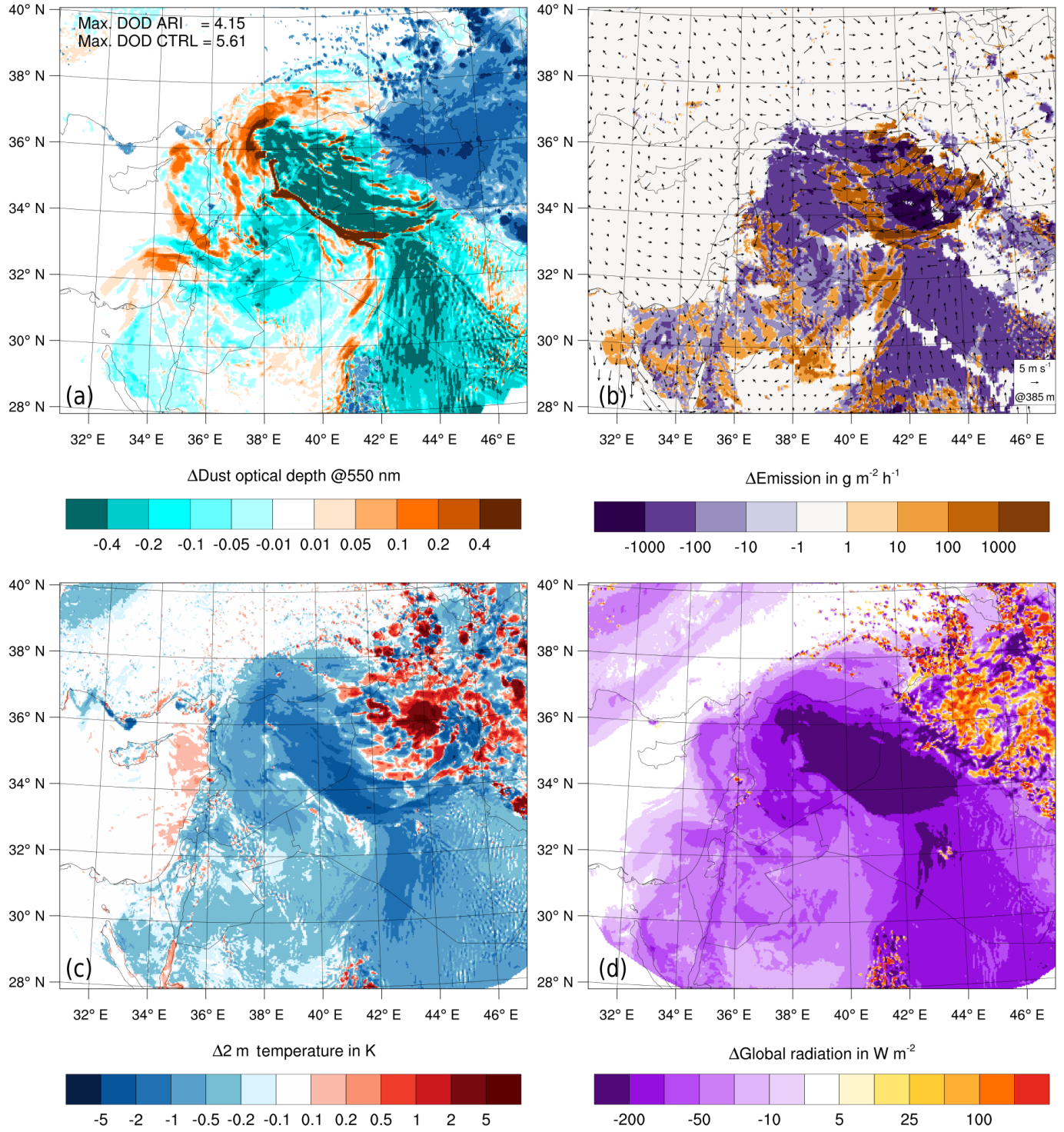

Figure 13. ICON-ART model results at 10:00 UTC, 7 September; layout and colour-coding as in Fig. 12.

The second analysis investigates the day-time radiative effect of mineral dust and is done at 10:00 UTC on 7 September (Fig. 13). This development stage is also analysed in Sect. 3.3. The dominant effect is the reduction in incoming shortwave solar radiation, while the increase in downwelling atmospheric longwave radiation is of a lesser magnitude (not shown). Resulting reductions in net global radiation are more than $200 \mathrm{~W} \mathrm{~m}^{-2}$ in the $\mathrm{CPO} 3$ region. The average value at the core of the $\mathrm{CPO} 3$ in the region bordered by the $34,36^{\circ} \mathrm{N}$ circles of latitude and $40,42^{\circ} \mathrm{E}$ meridians is $-281 \mathrm{~W} \mathrm{~m}^{-2}$ (Fig. 13d). The reduction in incoming energy leads to a widespread reduction in $2 \mathrm{~m}$ temperature of more than $2 \mathrm{~K}$. The average value in the aforementioned area is $-1.4 \mathrm{~K}$. The reduction in surface temperature is less than documented in other studies (Tegen et al., 2006; Helmert et al., 2007; Heinold et al., 2008). Possible explanations are the less absorptive character of mineral dust in ICON-ART with low values of the imaginary part of the refractive index in the shortwave region. Consequently, the dust mostly scatters radiation compared to absorbing it, thereby converting direct radiation to diffuse radiation. As the energy nonetheless reaches the surface, reductions in surface temperature due to mineral dust are smaller than those found in the other studies. A detailed analysis for the 10:00 UTC situation supports this hypothesis. Decreases in direct shortwave radiation are on the order of $600 \mathrm{~W} \mathrm{~m}^{-2}$ inside the $\mathrm{CPO} 3$ region. However, these are countered by increases in diffuse shortwave above $200 \mathrm{~W} \mathrm{~m}^{-2}$, giving a net reduction in shortwave radiation of approximately $400 \mathrm{~W} \mathrm{~m}^{-2}$ (not shown). Furthermore, the high amount of water vapour contained in the CPOs pos- 
sibly absorbs and scatters large quantities of solar radiation without dust already, thereby reducing the effect due to mineral dust. An observation which supports this hypothesis is that the reduction in $2 \mathrm{~m}$ temperature does not scale linearly with the difference in DOD between inflow and outflow regions of the MCS.

The reductions in surface temperature have a stabilizing effect on the boundary layer (Heinold et al., 2008). As a result of the increased boundary layer stable stratification dust emissions decrease almost homogeneously throughout the dust-affected region (Fig. 13b). In addition, this results in a reduced maximum DOD of 4.15 in ARI compared to 5.61 in CTRL for the whole domain. During the late afternoon with maximum boundary layer development, this difference increases. At 15:00 UTC ARI and CTRL show maximum DODs of 6.11 and 9.26, respectively. Another marked feature visible is the previously discussed difference in DOD at the CPO leading edges (Fig. 13a). As the feature is visible over more than $20 \mathrm{~h}$ and in connection with all CPOs, this confirms the observation of faster spreading CPOs in simulations including the mineral dust radiative feedback as proposed earlier. The streaks detectable inside the $\mathrm{CPO}$, where ARI shows higher values of DOD, can be attributed to shallow boundary layer convection, which develops earlier and more intensely in the $\mathrm{CPO} 3$ region in CTRL due to the lacking vertical stabilization (not shown). Consequently, due to the redistribution of dust by convection, the DOD field is more inhomogeneous in the CTRL run (not shown).

\section{Conclusions}

This study presents a large-domain, convection-permitting simulation of the September 2015 severe dust storm that allows the reproduction of the main atmospheric processes during this event. An active RST situation and the related MCSs and CPOs are shown to be responsible for the severe dust event in the EM. In addition, the interaction with an intense heat low, the inland-penetrating EM inflow, and the widespread occurrence of supercritical flow conditions and subsequent hydraulic jumps are suggested as important drivers for dust emission. While the importance of the heat low and convection for this event have been suggested elsewhere (Kerkmann et al., 2015; Solomos et al., 2017), the roles of the RST, EM inflow and hydraulic jumps as well as the detailed characteristics and interactions of individual CPOs are original findings of this study. Moreover, the mineral dust radiation interaction has been implemented as a new module in ICON-ART. Based on Mie scattering calculations, which are conducted off-line to calculate the mineral dust optical properties, the radiative transfer parameters used by ICON are calculated on-line in ART to account for the mineral dust radiative effect. A new, size-dependent parametrization of the mineral dust optical properties is proposed. Furthermore, to our knowledge this is the first study to investi- gate the mineral dust radiative effect on CPO structure. Summarizing, we are able to answer the research questions presented in the beginning as follows.

\subsection{Is the forecast of the dust event improved by running convection-permitting simulations?}

The convection-permitting simulation of the dust event with ICON-ART improves the forecast quality decisively. The driving meteorological systems and resulting dust emissions are captured in their horizontal, vertical and temporal structure as is shown by a comparison with satellite observations. The simulated DOD over Syria and Iraq is of a realistic magnitude with values above 2 throughout the main dust event region and maximum values above 6 . The transport to the northern part of the EM and Cyprus is modelled with DOD values above 2 , however with a $2^{\circ}$ longitudinal offset towards the east relative to the satellite data. Taking into account this offset, the vertical structure of the modelled dust plume arrival resembles lidar observations in Cyprus by Mamouri et al. (2016). The simulated DOD in this region is smaller than observed but up to 1 order of magnitude better than other operational global dust forecast models (see World Meteorological Organization dust forecast comparison, http://sds-was.aemet.es) at a longer forecast time. As the meteorological drivers are captured in detail, it is plausible that the remaining underestimation of dust concentration could be attributable to an out-of-date description of soil properties in the region due to the ongoing conflict (Solomos et al., 2017).

For the transport to the southern EM, a hydraulic jump is demonstrated to be of importance for dust emission in addition to the advection of the dense dust plumes into the region. It is captured by ICON-ART, albeit with reduced intensity compared to observations. Due to the out-of-date soil conditions in the Mesopotamia dust source region and an underdeveloped hydraulic jump phenomenon, dust transport into the southern EM is underestimated by 1 order of magnitude by ICON-ART. Modelled DODs are in the range of 0.5-1.5 over Israel, and $\mathrm{PM}_{10}$ concentrations reach up to $600 \mu \mathrm{g} \mathrm{m}^{-3}$ in Jerusalem. Nevertheless, the characteristic dust transport features are captured. The arrival of the main dust plume during the night of 8 September is simulated at $1 \mathrm{~km}$ height, and subsequent downward mixing increases surface dust concentrations.

\subsection{What is the synoptic situation enabling this extreme event and how does it relate to its exceptional character?}

The event is triggered by an active RST situation. The occurrence of the active RST situation at the beginning of September is unusually early, thereby explaining the extraordinariness of the event with respect to timing. Furthermore, the RST situation enables the interaction of multiple dust- 
emitting meteorological systems over the course of 3 days, which explains the extraordinariness of the event with respect to magnitude and spatial extent. In particular, the active RST situation favours a period of convectively active days with MCSs and associated CPOs. In addition, the formation of an intense heat low above Syria is facilitated. The cyclonic flow around the RST provides the basis for the transport of dust in southern and westerly directions on its downstream flank, which explains the exceptional transport direction of the dust plume into the EM from the east.

\subsection{What are the meteorological drivers responsible for pickup and long-range transport of mineral dust during this event?}

During the early morning hours of 6 September, a sharply defined CPO (CPO1) from an MCS over the Taurus mountain range interacts with a shallow but strong heat low forming in the boundary layer above Syria. Increased dust emissions occur as soon as turbulent mixing of the boundary layer sets in. Subsequently, the flow and dust plume created interact with the EM sea breeze penetrating inland. Downstream of the upper-tropospheric trough and with orographic support from the Zagros mountain range, a second MCS develops over the Turkey-Iraq-Iran border region from noon onwards. The MCS rapidly produces a CPO (CPO2) which travels west in the wake of the CPO1 and the heat low, again producing substantial dust emission over central Syria. The lifting caused by the gust front of the $\mathrm{CPO} 2$ triggers the initiation of deep convection over the Syria-Iraq border region, which becomes organized into an MCS around 18:00 UTC. The MCS is again located in a dynamically favourable position downstream of the quasi-stationary upper-tropospheric trough. It produces another CPO (CPO3) from 20:00 UTC onwards. The CPO3 subsequently counters and lifts the inflow from the Persian Gulf along the RST flank, thereby fuelling the MCS and enabling its sustained lifetime of more than $12 \mathrm{~h}$. During night-time, the $\mathrm{CPO} 3$ gains momentum and spreads towards west. With sunrise and the onset of boundary layer mixing, intense dust pickup occurs in the $\mathrm{CPO} 2$ and $\mathrm{CPO} 3$ region. The aged plume from the $\mathrm{CPO} 1$ and the $\mathrm{HL}$ is transported westward and south-westward along the EM coast, leading to a first arrival of dust in the region. During daytime on 7 September, the MCS dissipates. The dust plume connected to the $\mathrm{CPO} 3$ travels into a south-westerly direction supported by the flow on the downstream flank of the RST. The Dead Sea Rift Valley is passed by the merged dust plumes of the $\mathrm{CPO} 2$ and $\mathrm{CPO} 3$ after midnight on 8 September. During the night, the flow interacts with the complex orography. As a result, widespread supercritical flow conditions, and the subsequent hydraulic jumps, occur in the lee of orographic features. This flow phenomenon and the related dust emissions add to the extreme dust concentrations in the southern EM on 8 September. During daytime on 8 September, the dust plume is mostly stationary in the EM and influenced by the local circulation systems.

\subsection{How does the mineral dust radiative effect influence the dust event in general and the evolution of the CPOs in particular?}

Besides the feedbacks of the mineral dust radiation interaction which have been identified in the literature before, a previously undocumented effect is found inside the CPO regions. Systematically more intense CPOs and a faster propagation of the CPOs in the mineral dust radiation interaction run are modelled, posing interesting questions for further research to quantify the contributions of different physical processes to this effect.

In conclusion, this comprehensive case study underlines the need to explicitly represent deep moist convection in dust storm forecasting in accordance with the studies by Marsham et al. (2011) and Heinold et al. (2013). While Pantillon et al. (2016) propose a simple parametrization to represent the climatological effects of haboobs in coarserresolution models, the forecasting of severe events like the one investigated here can hardly be successful without explicit convection. Given the substantial impact of the event and the potential benefit of an early warning, forecasting centres around the world should consider running higherresolution dust forecasts on sufficiently large domains for the most vulnerable regions. More research is also needed into the multi-scale interactions between RSTs, heat lows and convection. Moreover, the role of hydraulic jumps for dust emission and transport in the Dead Sea valley appears an interesting subject for further study, which would greatly benefit from a denser observational network.

Data availability. The underlying data and model code can be obtained from the authors upon request. 


\section{Appendix A}
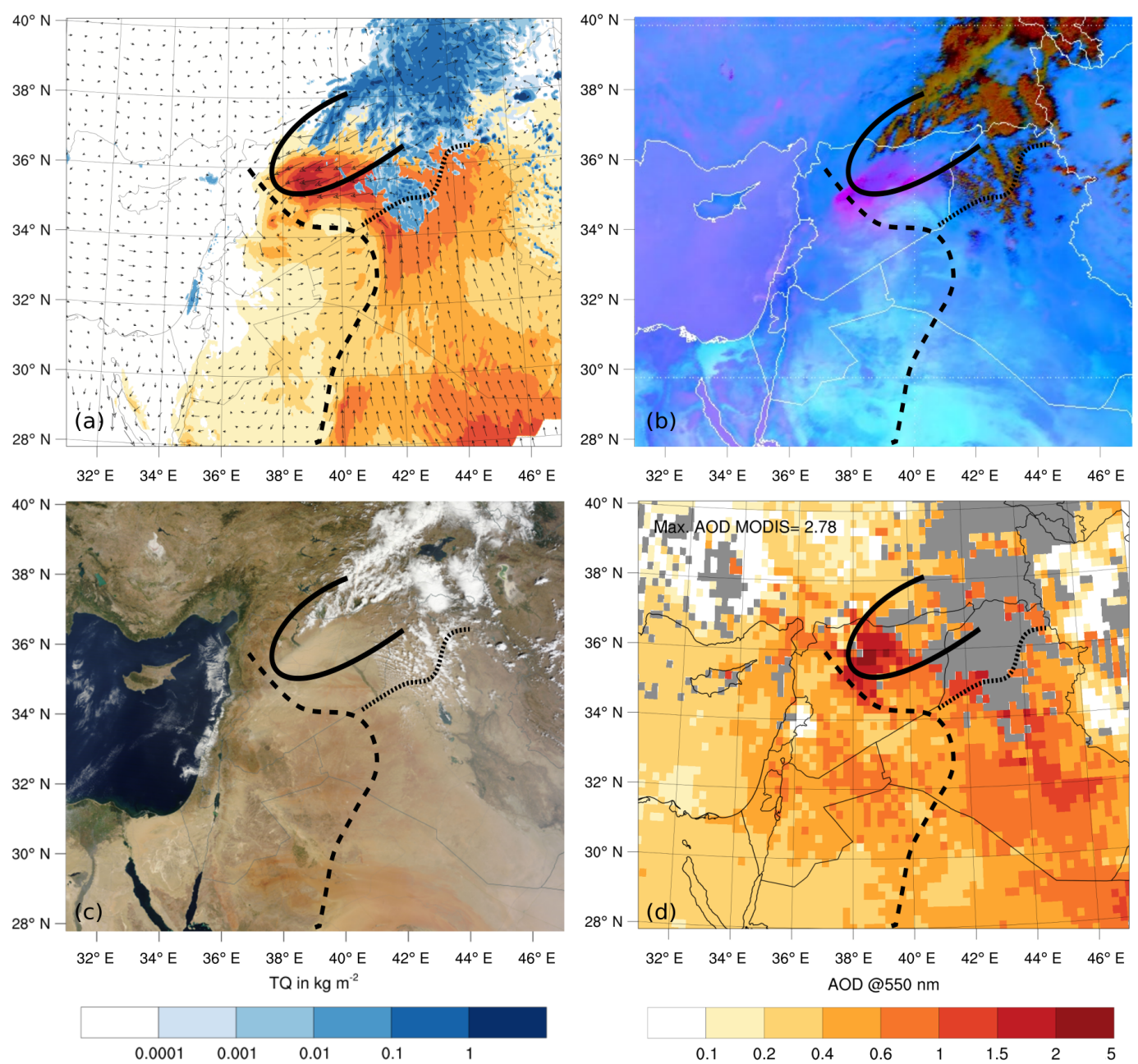

Figure A1. ICON-ART model results and satellite observations at 08:00 UTC, 6 September. The solid black line marks the CPO1, the dashed black line the EM inflow from 5 September and the dotted black line the frontal structure of inflow from the Persian Gulf. Displayed are (a) ICON-ART DOD, column-integrated hydrometeor content and wind velocity; (b) the SEVIRI RGB dust product (Kerkmann et al., 2015); (c) the Terra MODIS VIS satellite image, overpass at 08:15 UTC (NASA Worldview, 2016); (d) the Terra MODIS AOD retrieval using the DB2 algorithm (Levy and Hsu, 2015), overpass at 08:15 UTC. 

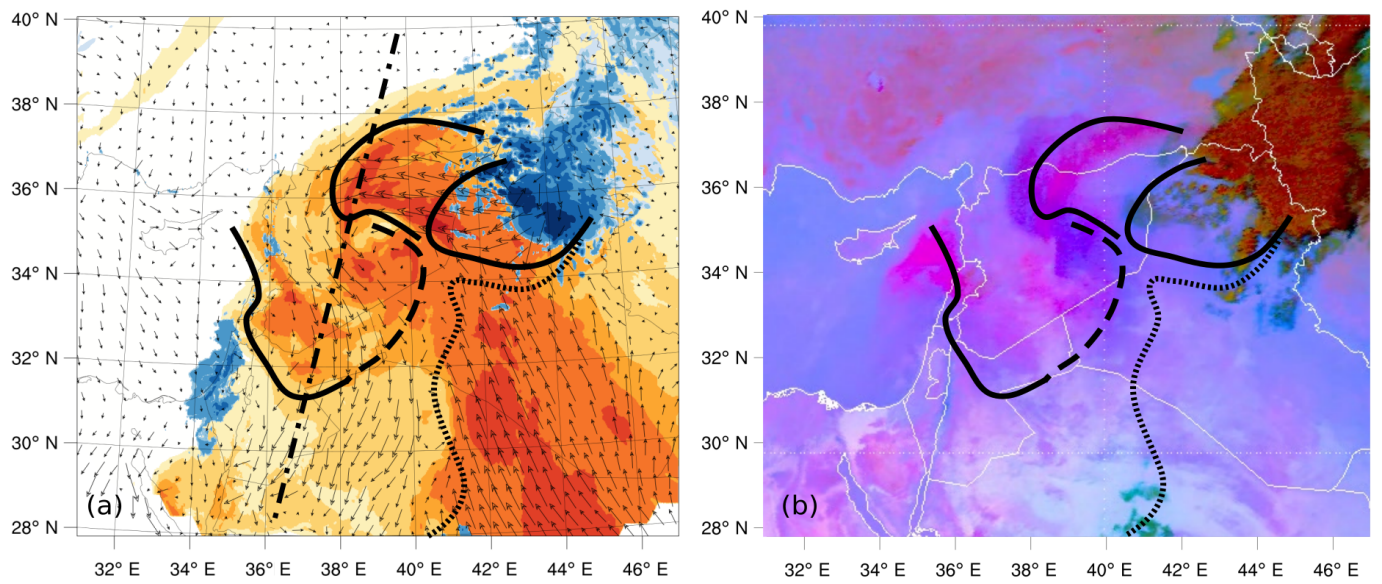

Figure A2. ICON-ART model results and EUMETSAT satellite observations at 00:00 UTC, 7 September. The axis and label bars for ICONART DOD and MODIS AOD as well as column-integrated hydrometeor content are equal to the ones used in Fig. 5 and are therefore not shown again. From west to east the solid black lines mark the leading edges of the CPO1, CPO2 and CPO3. The dashed line marks the aged EM inflow front. The dotted line marks the frontal region of inflow from the Persian Gulf. The chain dotted black line marks the CALIPSO ground track at 23:35 UTC, 6 September. Displayed are (a) ICON-ART DOD, column-integrated hydrometeor content and wind velocity, and (b) the SEVIRI RGB dust product (Kerkmann et al., 2015).

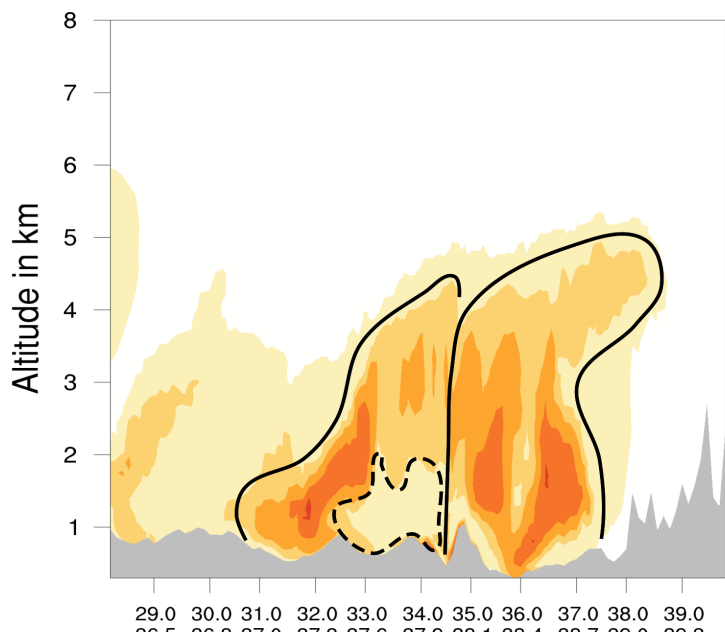

(a)

a) Extinction coefficient @ $550 \mathrm{~nm}$ in $\mathrm{km}^{-1}$

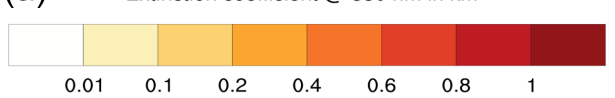

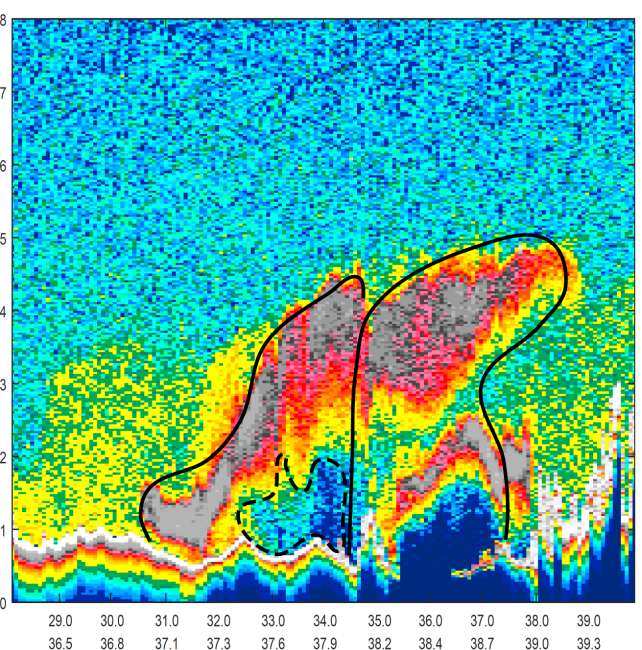

(b)

Total attenuated backscatter in $\mathrm{Mm}^{-1} \mathrm{sr}^{-1}$

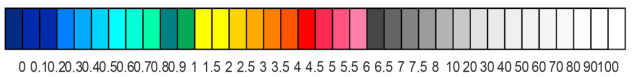

Figure A3. Vertical cross section of ICON-ART model results at 00:00 UTC, 7 September, and CALIPSO satellite observations from south to north along the ground track in Fig. A2. (a) ICON-ART mineral dust extinction coefficient. (b) Total attenuated backscatter as measured by CALIOP. No quantitative comparison is possible as two different measures are displayed. The southern solid black line marks the CPO1 and HL region. The dashed line marks the penetrating EM inflow. The northern solid black line marks the CPO2 region. 

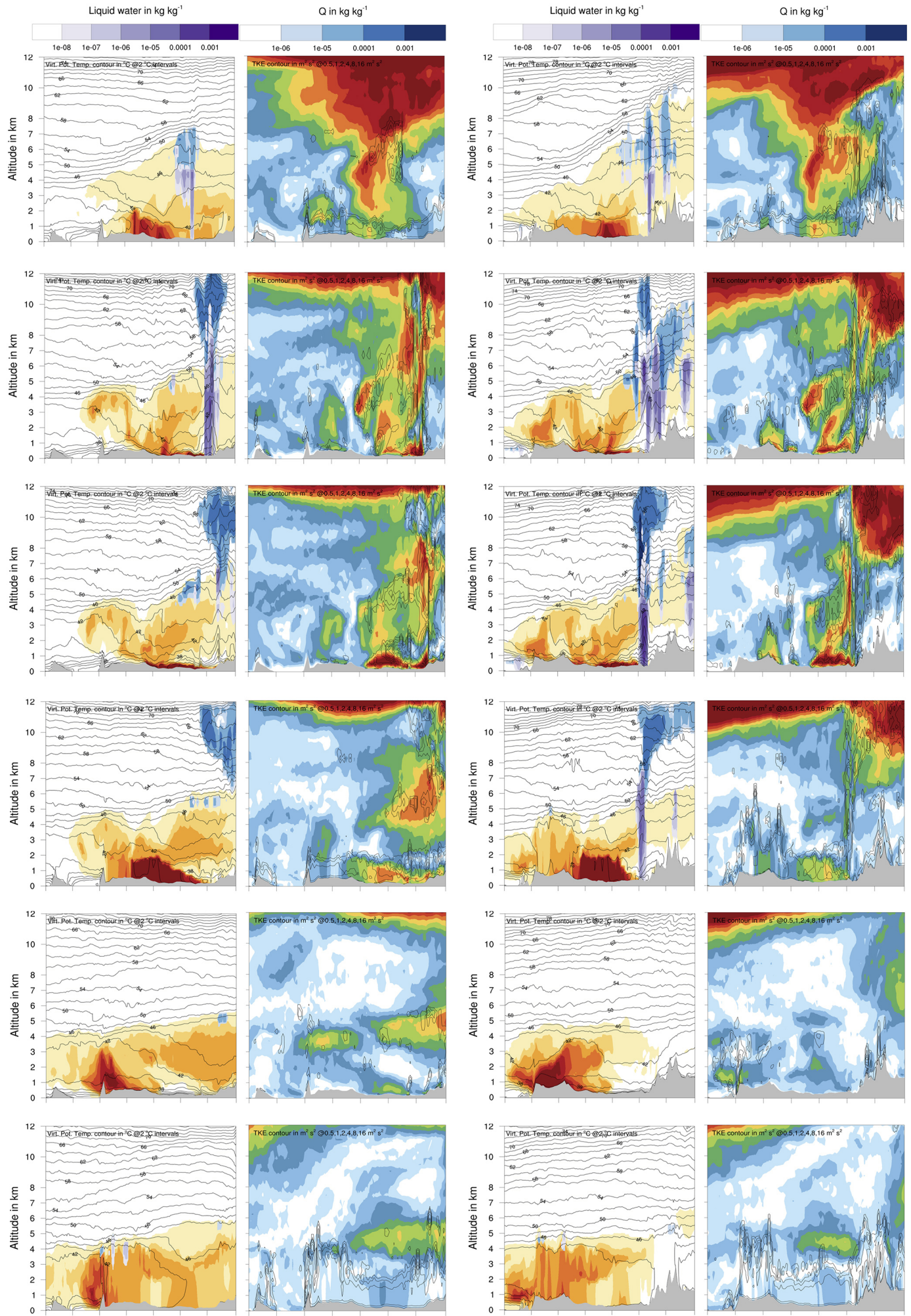

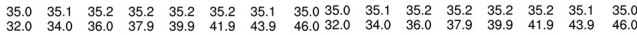
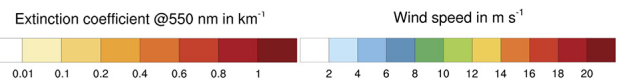

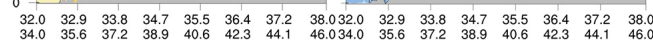

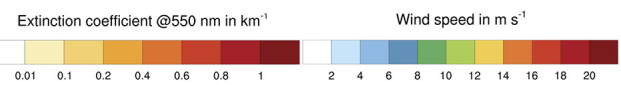

Figure A4. Vertical cross sections through ICON-ART model results along the transects in Fig. A6. The quantities displayed are the same as in Fig. 10; additionally shown are liquid water content and cloud ice, graupel and snow content Q. From top to bottom: 08:00 UTC, 6 September; 00:00, 03:00, 10:00 UTC, 7 September; 03:00, 11:00 UTC, 8 September. 

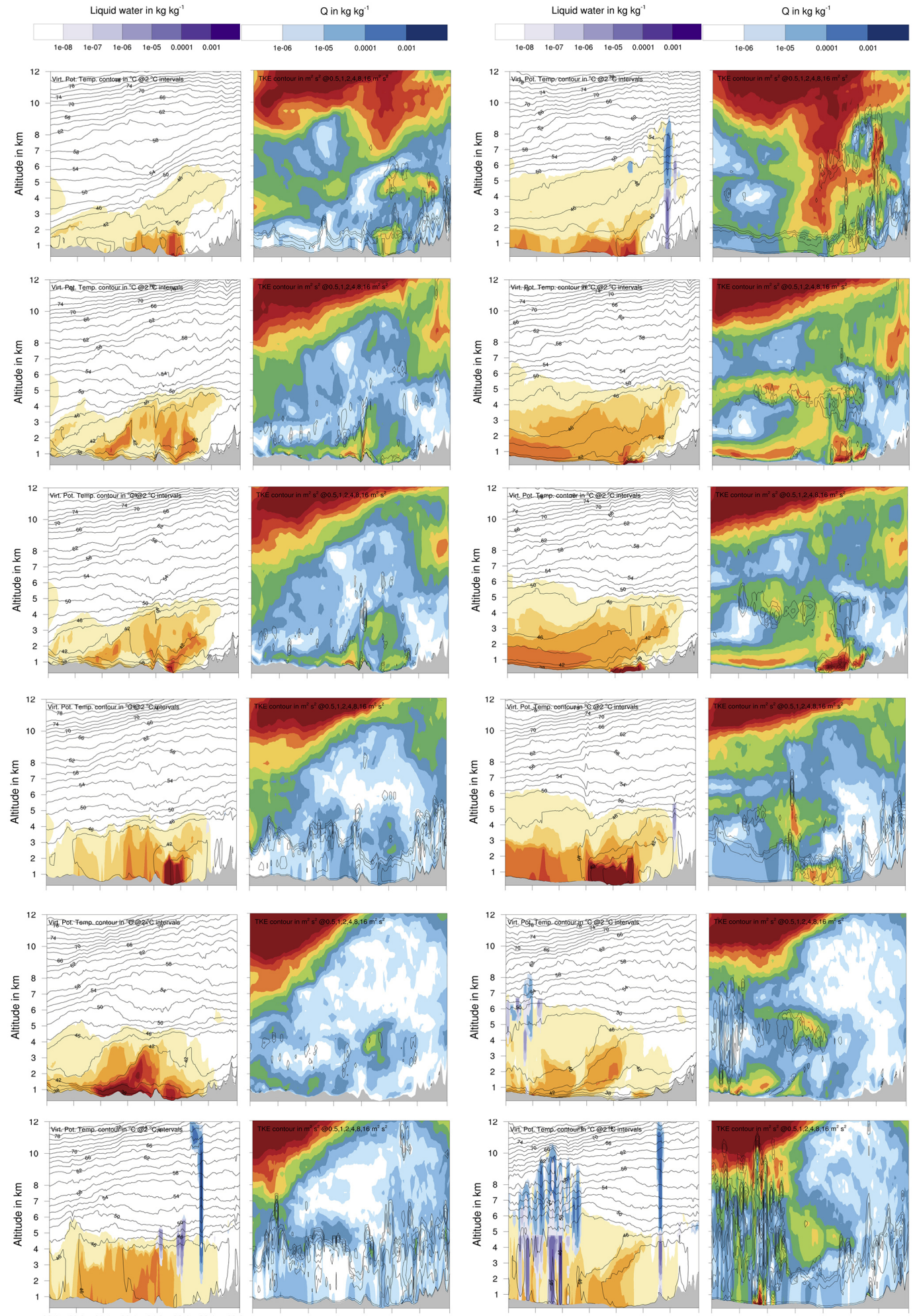

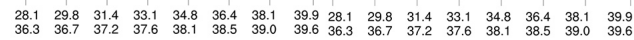

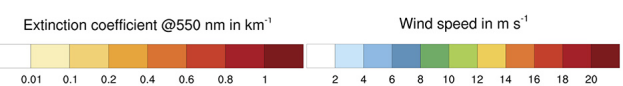

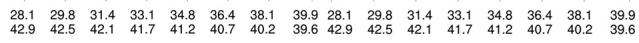

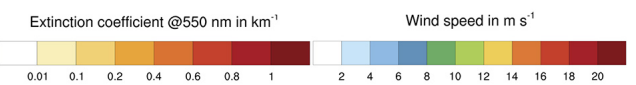

Figure A5. Vertical cross sections through ICON-ART model results; same as Fig. A4, but along the CALIPSO ground track at 23:35 UTC, 7 September, for the left-hand two-figure column. The right-hand two-figure column is along the CALIPSO ground track at 10:35 UTC, 7 September. 


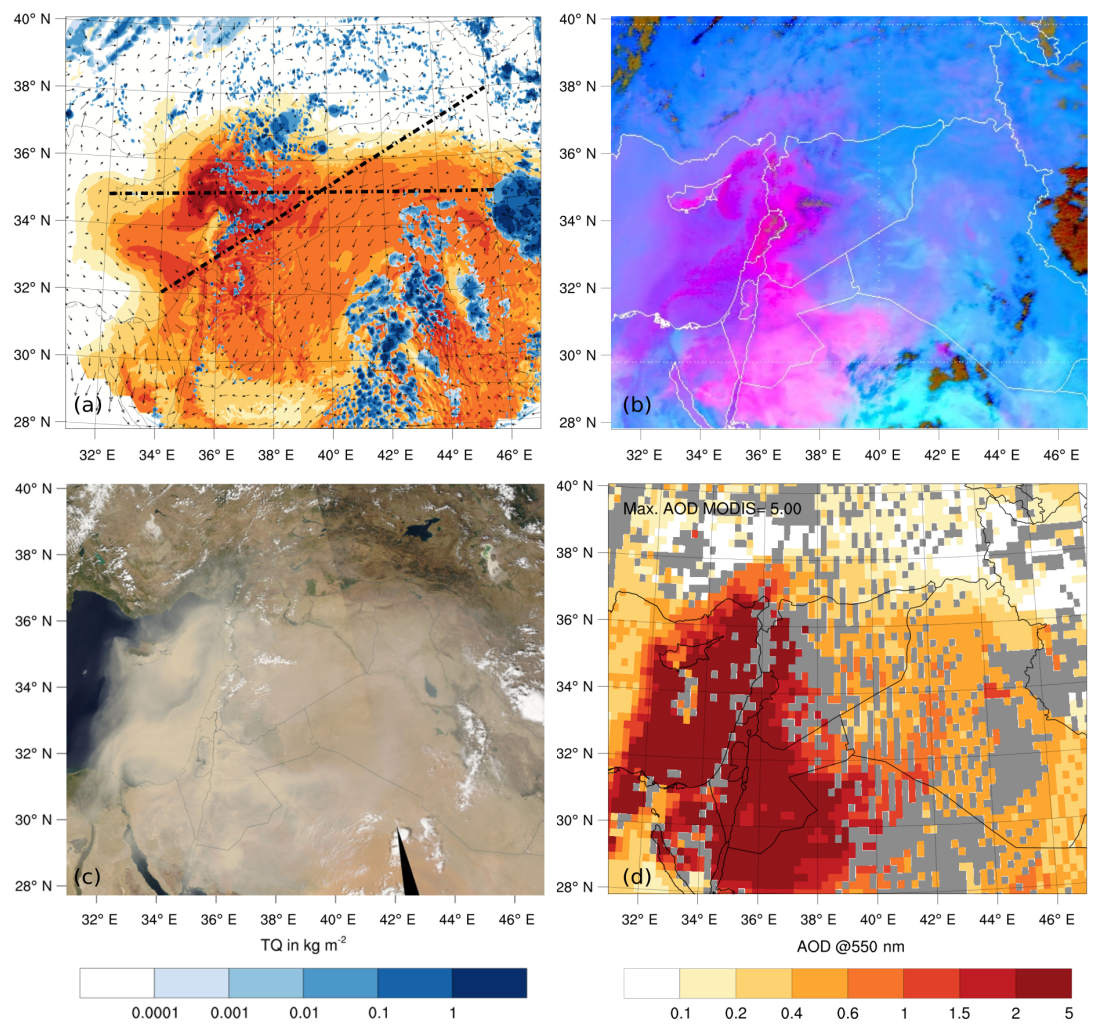

Figure A6. ICON-ART model results and satellite observations at 11:00 UTC, 8 September. The chain dotted black lines mark the locations of the cross sections displayed in Fig. A4 along the $35^{\circ} \mathrm{N}$ circle of latitude for the left-hand two-figure column and from $32^{\circ} \mathrm{N}, 34^{\circ} \mathrm{E}$ to $38^{\circ} \mathrm{N}, 46^{\circ} \mathrm{E}$ for the right-hand two-figure column. Displayed are (a) ICON-ART DOD, column-integrated hydrometeor content and wind velocity; (b) the SEVIRI RGB dust product (Kerkmann et al., 2015); the (c) Aqua MODIS VIS satellite image, overpass for the left part of the picture at 11:18 UTC (NASA Worldview, 2016); and (d) the Aqua MODIS AOD retrieval using the DB2 algorithm (Levy and Hsu, 2015), overpass for the left part of the picture at 11:18 UTC.
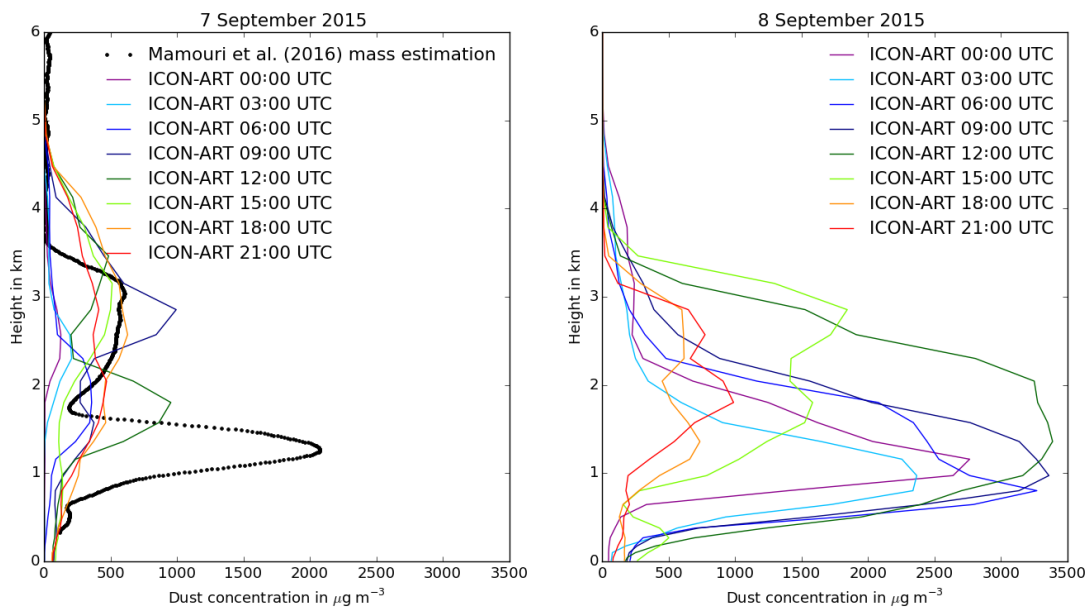

Figure A7. Mamouri et al. (2016) mass estimation from lidar observations for the EARLINET (European Aerosol Research Lidar Network) station in Limassol, Cyprus, for 19:00 UTC, 7 September, and ICON-ART model results for 7 and 8 September at $34.7^{\circ}$ N, $35.0^{\circ}$ E. Please note the $2^{\circ}$ eastward shift of the ICON-ART results shown compared to the Limassol observations due to the spatial offset of the dust plume; see Sect. 3.4. 


\section{The Supplement related to this article is available online at https://doi.org/10.5194/acp-17-13573-2017- supplement.}

Author contributions. The ICON-ART simulations were conducted and analysed by PG with the help of DR and CW. BV supervised the work and contributed to the discussion and design of the experiment. The Mie calculations for the mineral dust radiation interaction were conducted by PG and implemented in ART together with $\mathrm{DR}$ and $\mathrm{CW}$, based on input by BV. The Israeli station data were provided by PK and YL, who also aided the dust transport discussion as well as synoptic situation classification. PK contributed to the discussion of meteorological drivers and event stages and the mentoring of the work leading up to this publication. PG prepared the figures and the manuscript, which was improved by all authors.

Competing interests. The author Bernhard Vogel is a co-editor of ACP.

Special issue statement. This article is part of the special issue "Environmental changes and hazards in the Dead Sea region (NHESS/ACP/HESS/SE inter-journal SI)". It is not associated with a conference.

Acknowledgements. A special thanks goes to Christoph Kottmeier for his efforts in mentoring the work leading up to this publication. EUMETSAT and its training group (Jochen Kerkmann, HansPeter Roesli and Sancha Lancaster) are gratefully acknowledged for granting the right to use the MSG animation of the dust event. We would like to thank Tami Bond and Christoph Maetzler for making their MatLab-based Mie code publicly available. We thank Arnon Karnieli for his effort in establishing and maintaining the Sedé Boqer AERONET site. The MODIS aerosol optical depth datasets were acquired from the Level-1 Atmosphere Archive and Distribution System (LAADS) Distributed Active Archive Center (DAAC), located in the Goddard Space Flight Center in Greenbelt, Maryland (https://ladsweb.nascom.nasa.gov/). The authors acknowledge EARLINET for providing aerosol lidar profiles available from the EARLINET webpage. Furthermore, we would like to thank the referees and the editor Heini Wernli for their helpful remarks.

The article processing charges for this open-access publication were covered by a Research

Centre of the Helmholtz Association.

Edited by: Heini Wernli

Reviewed by: three anonymous referees

\section{References}

Alpert, P., Osetinsky, I., Ziv, B., and Shafir, H.: A new seasons definition based on classified daily synoptic systems: an example for the eastern Mediterranean, Int. J. Climatol., 24, 1013-1021, 2004.

Alpert, P., Egert, S., and Uzan, L.: The 7-13 September extreme dust downfall over the East Mediterranean A two ceilometers study, Geophys. Res. Abstr., EGU2016-3788, EGU General Assembly 2016, Vienna, Austria, 2016.

Arino, O., Bicheron, P., Achard, F., Latham, J., Witt, R., and Weber, J.-L.: The most detailed portrait of Earth, European Space Agency Bull, 136, 25-31, 2008.

Bangert, M., Nenes, A., Vogel, B., Vogel, H., Barahona, D., Karydis, V. A., Kumar, P., Kottmeier, C., and Blahak, U.: Saharan dust event impacts on cloud formation and radiation over Western Europe, Atmos. Chem. Phys., 12, 4045-4063, https://doi.org/10.5194/acp-12-4045-2012, 2012.

Bitan, A. and Sa'Aroni, H.: The horizontal and vertical extension of the Persian Gulf pressure trough, Int. J. Climatol., 12, 733-747, 1992.

Bohren, C. F. and Huffman, D. R.: Absorption and scattering of light by small particles, Wiley-VCH, Weinheim, Germany, repr. 2004 Edn., https://doi.org/10.1002/9783527618156, 1983.

Bond, T. C., Habib, G., and Bergstrom, R. W.: Limitations in the enhancement of visible light absorption due to mixing state, J. Geophys. Res.-Atmos., 111, D20211, https://doi.org/10.1029/2006JD007315, 2006.

Boucher, O., Randall, D., Artaxo, P., Bretherton, C., Feingold, G., Forster, P., Kerminen, V.-M., Kondo, Y., Liao, H., Lohmann, U., et al.: Clouds and Aerosols, in: The Physical Science Basis. Contribution of Working Group I to the Fifth Assessment Report of the Intergovernmental Panel on Climate Change, pp. 571-657, Cambridge University Press, Cambridge, UK and New York, NY, USA, 2013.

Carslaw, K. S., Boucher, O., Spracklen, D. V., Mann, G. W., Rae, J. G. L., Woodward, S., and Kulmala, M.: A review of natural aerosol interactions and feedbacks within the Earth system, Atmos. Chem. Phys., 10, 1701-1737, https://doi.org/10.5194/acp10-1701-2010, 2010.

Crouvi, O., Dayan, U., Amit, R., and Enzel, Y.: An Israeli haboob: Sea breeze activating local anthropogenic dust sources in the Negev loess, Aeolian Res., 24, 39-52, 2017.

Cuesta, J., Marsham, J. H., Parker, D. J., and Flamant, C.: Dynamical mechanisms controlling the vertical redistribution of dust and the thermodynamic structure of the West Saharan atmospheric boundary layer during summer, Atmos. Sci. Lett., 10, 34-42, 2009.

Dayan, U., Heffter, J., Miller, J., and Gutman, G.: Dust intrusion events into the Mediterranean basin, J. Appl. Meteorol., 30, 1185-1199, 1991.

Dayan, U., Ziv, B., Shoob, T., and Enzel, Y.: Suspended dust over southeastern Mediterranean and its relation to atmospheric circulations, Int. J. Climatol., 28, 915-924, 2008.

Drobinski, P., Flamant, C., Dusek, J., Flamant, P. H., and Pelon, J.: Observational Evidence And Modelling Of An Internal Hydraulic Jump At The Atmospheric Boundary-Layer Top During A Tramontane Event, Bound.-Lay. Meteorol., 3, 497-515, 2001.

Drobinski, P., Bastin, S., Janicot, S., Bock, O., Dabas, A., Delville, P., Reitebuch, O., and Sultan, B.: On the late northward propagation of the West African monsoon in summer 2006 in the region of Niger/Mali, J. Geophys. Res.-Atmos., 114, D09108, https://doi.org/10.1029/2008JD011159, 2009. 
Fécan, F., Marticorena, B., and Bergametti, G.: Parametrization of the increase of the aeolian erosion threshold wind friction velocity due to soil moisture for arid and semi-arid areas, Ann. Geophys., 17, 149-157, https://doi.org/10.1007/s00585-999-0149-7, 1999.

Ganor, E.: The composition of clay minerals transported to Israel as indicators of Saharan dust emission, Atmos. Environ. A-Gen., 25, 2657-2664, 1991.

Gasch, P.: Numerical simulations of an exceptional dust event in the Eastern Mediterranean including the mineral dust radiative feedback, Master's thesis, Karlsruhe Institute of Technology, 1$125,2016$.

Gkikas, A., Basart, S., Hatzianastassiou, N., Marinou, E., Amiridis, V., Kazadzis, S., Pey, J., Querol, X., Jorba, O., Gassó, S., and Baldasano, J. M.: Mediterranean intense desert dust outbreaks and their vertical structure based on remote sensing data, Atmos. Chem. Phys., 16, 8609-8642, https://doi.org/10.5194/acp16-8609-2016, 2016.

Gleick, P. H.: Water, drought, climate change, and conflict in Syria, Weather, Climate, and Society, 6, 331-340, 2014.

Heinold, B., Tegen, I., Schepanski, K., and Hellmuth, O.: Dust radiative feedback on Saharan boundary layer dynamics and dust mobilization, Geophys. Res. Lett., 35, L20817, https://doi.org/10.1029/2008GL035319, 2008.

Heinold, B., Knippertz, P., Marsham, J., Fiedler, S., Dixon, N., Schepanski, K., Laurent, B., and Tegen, I.: The role of deep convection and nocturnal low-level jets for dust emission in summertime West Africa: Estimates from convection-permitting simulations, J. Geophys. Res.-Atmos., 118, 4385-4400, 2013.

Helmert, J., Heinold, B., Tegen, I., Hellmuth, O., and Wendisch, M.: On the direct and semidirect effects of Saharan dust over Europe: A modeling study, J. Geophys. Res.-Atmos., 112, D13208, https://doi.org/10.1029/2006JD007444, 2007.

Highwood, E. J. and Ryder, C. L.: Dust Production Mechanisms, in: Mineral Dust, edited by: Knippertz, P. and Stuut, J.-B. W., chap. 11, 267-286, Springer, Dordrecht, the Netherlands, 2014.

Kahnert, M., Nousiainen, T., and Räisänen, P.: Mie simulations as an error source in mineral aerosol radiative forcing calculations, Q. J. Roy. Meteor. Soc., 133, 299-307, 2007.

Kalenderski, S. and Stenchikov, G.: High-resolution regional modeling of summertime transport and impact of African dust over the Red Sea and Arabian Peninsula, J. Geophys. Res.-Atmos., 121, 6435-6458, 2016.

Kerkmann, J., Lancaster, S., and Roesli, H. P.: Many parts of the Middle East were shrouded in a persistent dust cloud in early September, available at: http://www.eumetsat.int/website/home/ Images/ImageLibrary/DAT_2773503.html (last access: 8 August 2016), 2015.

Kishcha, P., Rieger, D., Metzger, J., Starobinets, B., Bangert, M., Vogel, H., Schättler, U., Corsmeier, U., Alpert, P., and Vogel, B.: Modelling of a strong dust event in the complex terrain of the Dead Sea valley during the passage of a gust front, Tellus B, 68, 29751, https://doi.org/10.3402/tellusb.v68.29751, 2016.

Knippertz, P.: Meteorological aspects of dust storms, in: Mineral Dust, edited by: Knippertz, P. and Stuut, J.-B. W., chap. 6, 121147, Springer, Dordrecht, the Netherlands, 2014.

Knippertz, P., Deutscher, C., Kandler, K., Müller, T., Schulz, O., and Schütz, L.: Dust mobilization due to density currents in the Atlas region: Observations from the Saharan Mineral Dust Ex- periment 2006 field campaign, J. Geophys. Res.-Atmos., 112, D21109, https://doi.org/10.1029/2007JD008774, 2007.

Krichak, S. O., Breitgand, J. S., and Feldstein, S. B.: A conceptual model for the identification of active Red Sea trough synoptic events over the southeastern Mediterranean, J. Appl. Meteorol. Clim., 51, 962-971, 2012.

Kubilay, N., Nickovic, S., Moulin, C., and Dulac, F.: An illustration of the transport and deposition of mineral dust onto the eastern Mediterranean, Atmos. Environ., 34, 1293-1303, 2000.

Levi, Y. and Rosenfeld, D.: Ice nuclei, rainwater chemical composition, and static cloud seeding effects in Israel, J. Appl. Meteorol., 35, 1494-1501, 1996.

Levy, R. and Hsu, C.: MODIS Atmosphere L2 Aerosol Product, Tech. rep., NASA, Goddard Space Flight Center, USA, https://doi.org/10.5067/MODIS/MOD04_L2.006, 2015.

Mamouri, R.-E., Ansmann, A., Nisantzi, A., Solomos, S., Kallos, G., and Hadjimitsis, D. G.: Extreme dust storm over the eastern Mediterranean in September 2015: satellite, lidar, and surface observations in the Cyprus region, Atmos. Chem. Phys., 16, 1371113724, https://doi.org/10.5194/acp-16-13711-2016, 2016.

Marsham, J. H., Knippertz, P., Dixon, N. S., Parker, D. J., and Lister, G.: The importance of the representation of deep convection for modeled dust-generating winds over West Africa during summer, Geophys. Res. Lett., 38, L16803, https://doi.org/10.1029/2011GL048368, 2011.

Mätzler, C.: MATLAB functions for Mie scattering and absorption, version 2, Tech. rep., Institute of Applied Physics, University of Bern, 1-26, 2002.

Metzger, J.: Wind Systems and Energy Balance in the Dead Sea Valley, PhD thesis, Karlsruhe Institute of Technology, Karlsruhe, 2016.

Miller, S. D., Kuciauskas, A. P., Liu, M., Ji, Q., Reid, J. S., Breed, D. W., Walker, A. L., and Mandoos, A. A.: Haboob dust storms of the southern Arabian Peninsula, J. Geophys. Res.-Atmos., 113, D01202, https://doi.org/10.1029/2007JD008550, 2008.

Mishchenko, M., Lacis, A., Carlson, B., and Travis, L.: Nonsphericity of dust-like tropospheric aerosols: Implications for aerosol remote sensing and climate modeling, Geophys. Res. Lett., 22, 1077-1080, 1995.

Mishchenko, M. I., Travis, L. D., Kahn, R. A., and West, R. A.: Modeling phase functions for dustlike tropospheric aerosols using a shape mixture of randomly oriented polydisperse spheroids, J. Geophys. Res.-Atmos., 102, 16831-16847, 1997.

Mlawer, E. J., Taubman, S. J., Brown, P. D., Iacono, M. J., and Clough, S. A.: Radiative transfer for inhomogeneous atmospheres: RRTM, a validated correlated-k model for the longwave, J. Geophys. Res.-Atmos., 102, 16663-16682, 1997.

Myhre, G. and Stordal, F.: Global sensitivity experiments of the radiative forcing due to mineral aerosols, J. Geophys. Res.-Atmos., 106, 18193-18204, 2001.

Nachtergaele, F. and Batjes, N.: Harmonized world soil database, Food and Agriculture Organization of the United Nations, Rome, 1-35, 2012.

NASA Earth Observatory: Dust Storm Sweeps Across Middle East, available at: http://earthobservatory.nasa.gov/NaturalHazards/ view.php?id=86571 (last access: 25 August 2016), 2015.

NASA Worldview: available at: https://worldview.earthdata.nasa. gov/ (last access: 8 August 2016), 2016. 
Nisantzi, A., Mamouri, R. E., Ansmann, A., Schuster, G. L., and Hadjimitsis, D. G.: Middle East versus Saharan dust extinctionto-backscatter ratios, Atmos. Chem. Phys., 15, 7071-7084, https://doi.org/10.5194/acp-15-7071-2015, 2015.

Notaro, M., Yu, Y., and Kalashnikova, O. V.: Regime shift in Arabian dust activity, triggered by persistent Fertile Crescent drought, J. Geophys. Res.-Atmos., 120, 10229-10249, https://doi.org/10.1002/2015JD023855, 2015.

Offer, Z. Y. and Goossens, D.: Ten years of aeolian dust dynamics in a desert region (Negev desert, Israel): analysis of airborne dust concentration, dust accumulation and the high-magnitude dust events, J. Arid Environ., 47, 211-249, 2001.

Osetinsky, I.: Climate changes over the E. Mediterranean - A synoptic systems classification approach, $\mathrm{PhD}$ thesis, Tel Aviv University, Tel Aviv, 2006.

Otto, S., Bierwirth, E., Weinzierl, B., Kandler, K., Esselborn, M., Tesche, M., Schladitz, A., Wendisch, M., and Trautmann, T.: Solar radiative effects of a Saharan dust plume observed during SAMUM assuming spheroidal model particles, Tellus B, 61, 270 296, 2009.

Pantillon, F., Knippertz, P., Marsham, J. H., Panitz, H.-J., and Bischoff-Gauss, I.: Modeling haboob dust storms in large-scale weather and climate models, J. Geophys. Res.-Atmos., 121, 2090-2109, 2016.

Pérez, C., Nickovic, S., Pejanovic, G., Baldasano, J. M., and Özsoy, E.: Interactive dust-radiation modeling: A step to improve weather forecasts, J. Geophys. Res.-Atmos., 111, D16206, https://doi.org/10.1029/2005JD006717, 2006.

Petty, G. W.: A first course in atmospheric radiation, Sundog Pub, Madison, USA, 2006.

Petzold, A., Rasp, K., Weinzierl, B., Esselborn, M., Hamburger, T., Dörnbrack, A., Kandler, K., Schütz, L., Knippertz, P., Fiebig, M., and Virkkula, A.: Saharan dust absorption and refractive index from aircraft-based observations during SAMUM 2006, Tellus B, 61, 118-130, 2009.

Raupach, M.: Dry deposition of gases and particles to vegetation, Clean Air, 27, 200-203, 1993.

Redl, R., Knippertz, P., and Fink, A. H.: Weakening and moistening of the summertime Saharan heat low through convective cold pools from the Atlas Mountains, J. Geophys. Res.-Atmos., 121, 3907-3928, 2016.

Rémy, S., Benedetti, A., Bozzo, A., Haiden, T., Jones, L., Razinger, M., Flemming, J., Engelen, R. J., Peuch, V. H., and Thepaut, J. N.: Feedbacks of dust and boundary layer meteorology during a dust storm in the eastern Mediterranean, Atmos. Chem. Phys., 15, 12909-12933, https://doi.org/10.5194/acp-15-129092015, 2015.

Rieger, D.: Der Einfluss von natürlichem Aerosol auf Wolken, PhD thesis, Karlsruhe Institute of Technology, Karlsruhe, 2016.

Rieger, D., Bangert, M., Bischoff-Gauss, I., Förstner, J., Lundgren, K., Reinert, D., Schröter, J., Vogel, H., Zängl, G., Ruhnke, R., and Vogel, B.: ICON-ART 1.0 - a new online-coupled model system from the global to regional scale, Geosci. Model Dev., 8, 1659-1676, https://doi.org/10.5194/gmd-8-1659-2015, 2015.

Rieger, D., Steiner, A., Bachmann, V., Gasch, P., Förstner, J., Deetz, K., Vogel, B., and Vogel, H.: Impact of the 4 April 2014 Saharan dust outbreak on the photovoltaic power generation in Germany, Atmos. Chem. Phys. Discuss., https://doi.org/10.5194/acp-2017441, in review, 2017.
Seifert, A. and Beheng, K. D.: A double-moment parameterization for simulating autoconversion, accretion and selfcollection, Atmos. Res., 59, 265-281, 2001.

Seifert, A. and Beheng, K.: A two-moment cloud microphysics parameterization for mixed-phase clouds. Part 1: Model description, Meteorol. Atmos. Phys., 92, 45-66, 2006.

Shao, Y. and Lu, H.: A simple expression for wind erosion threshold friction velocity, J. Geophys. Res.-Atmos., 105, 22437-22443, 2000.

Shao, Y., Wyrwoll, K.-H., Chappell, A., Huang, J., Lin, Z., McTainsh, G. H., Mikami, M., Tanaka, T. Y., Wang, X., and Yoon, S.: Dust cycle: An emerging core theme in Earth system science, Aeolian Res., 2, 181-204, https://doi.org/10.1016/j.aeolia.2011.02.001, 2011a.

Singer, A., Ganor, E., Dultz, S., and Fischer, W.: Dust deposition over the Dead Sea, J. Arid. Environ., 53, 41-59, 2003.

Solomos, S., Ansmann, A., Mamouri, R.-E., Binietoglou, I., Patlakas, P., Marinou, E., and Amiridis, V.: Remote sensing and modelling analysis of the extreme dust storm hitting the Middle East and eastern Mediterranean in September 2015, Atmos. Chem. Phys., 17, 4063-4079, https://doi.org/10.5194/acp17-4063-2017, 2017.

Spyrou, C., Kallos, G., Mitsakou, C., Athanasiadis, P., Kalogeri, C., and Iacono, M. J.: Modeling the radiative effects of desert dust on weather and regional climate, Atmos. Chem. Phys., 13, 54895504, https://doi.org/10.5194/acp-13-5489-2013, 2013.

Stanelle, T., Vogel, B., Vogel, H., Bäumer, D., and Kottmeier, C.: Feedback between dust particles and atmospheric processes over West Africa during dust episodes in March 2006 and June 2007, Atmos. Chem. Phys., 10, 10771-10788, https://doi.org/10.5194/acp-10-10771-2010, 2010.

Tegen, I. and Lacis, A. A.: Modeling of particle size distribution and its influence on the radiative properties of mineral dust aerosol, J. Geophys. Res.-Atmos., 101, 19237-19244, 1996.

Tegen, I., Heinold, B., Todd, M., Helmert, J., Washington, R., and Dubovik, O.: Modelling soil dust aerosol in the Bodélé depression during the BoDEx campaign, Atmos. Chem. Phys., 6, 43454359, https://doi.org/10.5194/acp-6-4345-2006, 2006.

The Weather Channel: Intense Middle East Dust Storm Kills At Least 5, Sickens Hundreds, available at: https://weather.com/news/news/severe-middle-east-sandstormdust-storm-jordan-israel-lebanon-syria-iraq (last access: 8 August 2016), 2015.

Times Of Israel: Heavy dust blankets country for second day as intense heat joins in, available at: http://www.timesofisrael.com/heavy-dust-to-blanket-countryfor-second-day-as-intense-heat-joins-in/ (last access: 25 August 2016), 2015.

Tsvieli, Y. and Zangvil, A.: Synoptic climatological analysis of wet and dry Red Sea troughs over Israel, Int. J. Climatol., 25, 19972015, 2005.

Vogel, B., Hoose, C., Vogel, H., and Kottmeier, C.: A model of dust transport applied to the Dead Sea area, Meteorol. Z., 15, 611624, 2006.

Voss, K. A., Famiglietti, J. S., Lo, M., Linage, C., Rodell, M., and Swenson, S. C.: Groundwater depletion in the Middle East from GRACE with implications for transboundary water management in the Tigris-Euphrates-Western Iran region, Water Resour. Res., 49, 904-914, 2013. 
Vries, A., Tyrlis, E., Edry, D., Krichak, S., Steil, B., and Lelieveld, J.: Extreme precipitation events in the Middle East: dynamics of the Active Red Sea Trough, J. Geophys. Res.-Atmos., 118, 70877108, 2013.

Wagner, R., Ajtai, T., Kandler, K., Lieke, K., Linke, C., Müller, T., Schnaiter, M., and Vragel, M.: Complex refractive indices of Saharan dust samples at visible and near UV wavelengths: a laboratory study, Atmos. Chem. Phys., 12, 2491-2512, https://doi.org/10.5194/acp-12-2491-2012, 2012.
Zängl, G., Reinert, D., Rípodas, P., and Baldauf, M.: The ICON (ICOsahedral Non-hydrostatic) modelling framework of DWD and MPI-M: Description of the non-hydrostatic dynamical core, Q. J. Roy. Meteor. Soc., 141, 563-579, 2015. 